\title{
Apolipoprotein E - Low Density Lipoprotein Receptor Interaction Affects Spatial Memory Retention and Brain ApoE Levels in an Isoform-Dependent Manner
}

\author{
Lance A. Johnson ${ }^{1}$, Reid H.J. Olsen ${ }^{1}$, Louise S. Merkens ${ }^{4}$, Andrea DeBarber ${ }^{5}$, Robert D. \\ Steiner6, Patrick M. Sullivan ${ }^{7}$, Nobuyo Maeda ${ }^{8}$, and Jacob Raber ${ }^{1,2,3}$ \\ ${ }^{1}$ Department of Behavioral Neuroscience, Oregon Health \& Science University, Portland, Oregon \\ 2 Department of Neurology, Oregon Health \& Science University, Portland, OR \\ 3 Division of Neuroscience, ONPRC, Oregon Health \& Science University, Beaverton, OR \\ ${ }^{4}$ Department of Pediatrics, Oregon Health \& Science University, Portland, OR \\ ${ }^{5}$ Department of Physiology and Pharmacology, Oregon Health \& Science University (OHSU), \\ Portland, OR \\ ${ }^{6}$ Departments of Pediatrics and Molecular and Medical Genetics, Institute on Development and \\ Disability, Doernbecher Children's Hospital, Oregon Health \& Science University, Portland, OR \\ and Marshfield Clinic Research Foundation, Marshfield, WI \\ ${ }^{7}$ Department of Medicine, Duke University, Durham VA Medical Center and GRECC, Durham, \\ NC \\ ${ }^{8}$ Department of Pathology \& Laboratory Medicine, University of North Carolina, Chapel Hill, NC
}

\section{Abstract}

Human apolipoprotein E (apoE) exists in three isoforms: apoE2, apoE3 and apoE4. APOE $\varepsilon 4$ (E4) is a major genetic risk factor for cardiovascular disease (CVD) and Alzheimer's disease (AD). ApoE mediates cholesterol metabolism by binding various receptors. The low-density lipoprotein receptor (LDLR) has a high affinity for apoE, and is the only member of its receptor family to demonstrate an apoE isoform specific binding affinity (E4>E3>>E2). Evidence suggests that a functional interaction between apoE and LDLR influences the risk of CVD and AD. We hypothesize that the differential cognitive effects of the apoE isoforms are a direct result of their varying interactions with LDLR. To test this hypothesis, we have employed transgenic mice that express human apoE2, apoE3, or apoE4, and either human LDLR (hLDLR) or no LDLR (LDLR-/ -). Our results show that plasma and brain apoE levels, cortical cholesterol, and spatial memory are all regulated by isoform-dependent interactions between apoE and LDLR. Conversely, both anxiety-like behavior and cued associative memory are strongly influenced by $A P O E$ genotype, but these processes appear to occur via an LDLR-independent mechanism. Both the lack of LDLR

(C) 2013 Elsevier Inc. All rights reserved.

Corresponding Author: Jacob Raber, PhD Dept of Behavioral Neuroscience, L470, Oregon Health and Science University, 3181 SW Sam Jackson Pkwy, Portland, OR 97239 Phone: 503-494-1424; Fax: 503-494-6877; raberj@ ohsu.edu.

Publisher's Disclaimer: This is a PDF file of an unedited manuscript that has been accepted for publication. As a service to our customers we are providing this early version of the manuscript. The manuscript will undergo copyediting, typesetting, and review of the resulting proof before it is published in its final citable form. Please note that during the production process errors may be discovered which could affect the content, and all legal disclaimers that apply to the journal pertain.

Conflicts of Interest

There are no conflicts of interest to report. 
and the interaction between E4 and the LDLR were associated with significant impairments in the retention of long term spatial memory. Finally, levels of hippocampal apoE correlate with long term spatial memory retention in mice with human LDLR. In summary, we demonstrate that the apoE-LDLR interaction affects regional brain apoE levels, brain cholesterol, and cognitive function in an apoE isoform-dependent manner.

\section{Keywords}

Apolipoprotein E; Low density lipoprotein receptor; memory; hippocampus; cholesterol; apoE; LDLR; Alzheimer's

\section{Introduction}

Abnormalities in lipid metabolism are strongly linked to several diseases such as cardiovascular disease (CVD) and Alzheimer's disease (AD) (Yusuf et al., 2004, Gamba et al., 2012). Efficient cholesterol transport is an important part of the cellular remodeling that underlies synaptic plasticity and breakdown of this process has been proposed to contribute to dementia (Gamba et al., 2012, Martin et al., 2010). Two essential regulatory components of cholesterol metabolism are apolipoprotein $\mathrm{E}(\mathrm{apoE})$ and the low density lipoprotein receptor (LDLR).

ApoE is an essential component of lipoprotein particles in both the brain and periphery, and exists in three isoforms in the human population: $\mathrm{APO} \varepsilon * 2(\mathrm{E} 2), \mathrm{APO} \varepsilon * 3(\mathrm{E} 3)$, and $\mathrm{APO} \varepsilon * 4$ (E4) (Raber et al., 2004, Mahley and Rall, 2000). While the isoforms only differ from one another by one or two amino acids, they show dramatic differences in structure, function and disease-associated risk. For instance, E4 is associated with an increased risk of CVD (Mahley and Rall, 2000) and AD (Raber et al., 2004). ApoE is a primary component of various lipoprotein particles, and binds to a variety of cell surface receptors (Hauser et al., 2011). One such receptor is LDLR, a trans-membrane receptor expressed in the liver, brain and other tissues (Jeon and Blacklow., 2005). ApoE and LDLR play critical roles in the regulation of cholesterol metabolism in the peripheral vasculature (Go and Mani, 2012) and likely play a similarly critical role in the brain.

The apoE-LDLR interaction appears critical in both CVD and AD. For example, the disparities in CVD risk usually associated with $A P O E$ genotype disappear in patients who lack functioning LDLR, suggesting that the diseases-modifying effects of the apoE isoforms depend on the presence of a fully functioning LDLR protein (Vermissen et al., 2011). In mice, introduction of human LDLR results in higher plasma cholesterol and increased cardiovascular complications in the presence of E4 (Altenburg et al., 2007, Malloy et al., 2004, Johnson et al., 2013). This effect does not occur in mice expressing E3, and in the presence of E2 actually lowers cholesterol and improves cardiovascular outcomes (Knouff et al., 2001).

In the context of $\mathrm{AD}$, the risk of disease is modified by various LDLR polymorphisms (Gopalraj et al., 2005, Zou et al., 2008). Furthermore, the risk associated with a certain LDLR polymorphism differs dramatically depending on the patients' APOE genotype, implying that a functional interaction between apoE and LDLR determines AD risk (Cheng et al., 2004, Retz et al., 2001).

In contrast to cardiovascular function, it is unclear whether apoE isoform-dependent interactions with human LDLR affect brain function. Therefore, in this study we employed a humanized mouse model expressing both human apoE isoforms (targeted replacement) and 
human LDLR to study the effects of the apoE-LDLR interactions on brain function. We demonstrate that the apoE-LDLR interaction affects regional brain apoE levels, brain cholesterol, and cognitive function in an apoE isoform-dependent manner.

\section{Methods}

\section{Experimental animals}

Mice expressing human apoE isoforms under control of the mouse apoE promoter (targeted replacement mice) (Sullivan et al., 1997, Sullivan et al., 1998, Knouff et al., 1999) were crossed with mice deficient in LDLR (Ishibashi et al., 1993, Knouff et al., 2004) or with mice hemizygous for a targeted replacement of the mouse LDLR gene with the stabilized human LDLR minigene (Malloy et al., 2004, Knouff et al., 2001). All mice were backcrossed for at least 6 generations to the C57BL/6 background prior to crossing them for the experiments in the current study. LDLR deficient $\left(\mathrm{LDLR}^{-/}\right)$and hemizygous human LDLR $\left(\mathrm{LDLR}^{\mathrm{h} /-}\right)$ mice of similar APOE genotype were all littermates with a common genetic background obtained from crossbreeding (example: E2/E2 LDLR ${ }^{\mathrm{h} /} \times \mathrm{E} 2 / \mathrm{E} 2$ $\mathrm{LDLR}^{-/}$). The mice were fed normal chow diet ad libitum (5.3\% fat and $0.02 \%$ cholesterol, Prolab IsoPro RMH 3000; Agway Inc). All analyses were carried out at 10-12 months of age ( $n=6$ to 12). Only female mice were used for the current study. All procedures complied with the National Institutes of Health Guide for the Care and Use of Laboratory Animals and with IACUC approval at Oregon Health \& Sciences University.

\section{Behavioral Analyses}

Anxiety (Elevated Zero Maze, Day 1)-The elevated zero maze enclosure (Kinder Scientific, Poway, CA) consisted of four sections ( $6 \mathrm{~cm}$ wide), alternating between open and closed environments. Mice were placed into an open area of the maze and allowed to explore for 10 minutes. An automated photobeam detection method (Kinder Scientific, Poway, CA) was used to track mouse movements: distance moved ( $\mathrm{cm})$, time spent in the open and closed areas (s) as well as crossings between environments.

Novel Object Recognition (Days 2-5)—Mice were placed into a brightly lit square arena $(40.6 \times 40.6 \mathrm{~cm})$ and habituated to the open field arena over two days, with a one 10minute trial per day. On the third day, mice were exposed to the arena containing two identical objects (small orange hexagonal prisms) placed $15 \mathrm{~cm}$ from the adjacent walls and $10 \mathrm{~cm}$ apart for 15 minutes. On day five, one of the identical objects ("familiar") was replaced with a novel object (small green triangular prism) of identical dimensions. Movement and exploration were tracked and analyzed with video software from Noldus Information Technologies (Ethovision XT 7, Wageningen, The Netherlands). Clear visuospatial orientation to the object, within $2 \mathrm{~cm}$ proximity, as well as interaction with the object was coded as exploratory behavior, and the percent time spent exploring the novel versus familiar object was calculated.

Spatial Learning and Memory in the Water Maze (Days 8-15)—The water maze consisted of a circular pool (diameter $140 \mathrm{~cm}$ ), filled with opaque water (white chalk added, $24^{\circ} \mathrm{C}$ ) divided conceptually into four quadrants. Mice were first trained to locate an "escape" platform (plexiglass circle, $6 \mathrm{~cm}$ radius) submerged $2 \mathrm{~cm}$ below the surface of the water, by the use of a cue (a colored cylinder, $2.5 \mathrm{~cm}$ radius, $8 \mathrm{~cm}$ height) during the "Visible" trials (days 8-9). Mice were given two sessions per day (separated by three hours) consisting of two trials each (separated by 10 minutes). The location of the platform was moved for each session between the four quadrants to avoid procedural biases in task learning. Subsequent to the "Visible Platform" trials, mice were trained to locate the platform sans cue during the "Hidden Platform" trails, which required the mice to rely on extra-maze cues for spatial 
reference and orientation. Extra-maze cues consisted of four large $(50 \times 50 \mathrm{~cm})$ cues of different shapes and color combinations, positioned at the borders of the four quadrants. Cues were placed $100 \mathrm{~cm}$ from the ground, and $90 \mathrm{~cm}$ away from the edge of the pool. The platform was not rotated during the Hidden Platform trials, remaining in the "Target" quadrant. Spatial memory retention was assessed 24 hours following the conclusion of the second and fourth sessions of "Hidden Platform" training, as well as 72 hours following the final "Hidden Platform" training session. The submerged platform was removed and spatial memory retention assessed during these "Probe" trials by analyzing the time spent swimming in the target quadrant compared to the time spent in the three non-target quadrants.

Associative Learning and Memory (Days 16-17) -In this task, mice learned to associate a conditioned stimulus (CS, e.g. the environmental context, or a discrete cue tone) with a mild foot shock (unconditioned stimulus, US). Freezing, defined as somatomotor immobility with the exception of respiration, is considered a post-exposure fear response, and is a widely used indicator of conditioned fear (Maren 2001). Mice were trained and tested using a Med Associates mouse fear conditioning system (PMED-VFCNIR-M, Med Associates, St. Albans, Vermont) utilizing Med Associates VideoFreeze automated scoring system. Mice were placed inside a dark fear conditioning chamber, and chamber lights were turned on at zero seconds, followed by a 160 second habituation period and a subsequent 30 -second $(80 \mathrm{~dB})$ tone (cue). A 2-second $0.35 \mathrm{~mA}$ foot shock was administered at 188 seconds, co-terminating with the tone at 190 seconds. This series was repeated for a total of four times. Twenty four hours later, contextual associative memory was assessed during re-exposure to the training environment for 600 seconds. Three hours later, mice were exposed to a modified environment (scented with vanilla extract, novel floor texture covering the shock-grid, and rounded walls), allowed to habituate to it for 160 seconds, and they were then exposed to the sound cue for a second period of 30 seconds. This series was repeated a total of five times. Motion during shock (proprietary index, Med Associates) during the training day was measured to account for sensor-motor differences in response to the aversive stimulus. Associative learning was measured as the percent time spent freezing in response to the environment (contextual) or tone (cued).

\section{Gene expression}

mRNA was purified from mouse cortex using an Automated Nucleic Acid Workstation ABI 6700, and real-time PCR was performed using an ABI PRISM 7700 Sequence Detector (Applied Biosystems). In order to compare to murine $L D L R$ expression, a primer extension assay was designed to quantify both human and mouse message simultaneously using a primer 5'-GGA GCA CGT CTT GGG GGG ACA GCC T-3' corresponding to a shared sequence within exon 3 of the two $L D L R$ genes. Primer extension was terminated by ddCTP, resulting in murine message extension by 5 bp and human message extension by $3 \mathrm{bp}$. The 30 - and 28 -bp fragments were separated in a denaturing $20 \%$ polyacrylamide gel. A primer 5'-GCA GCG AAC TTT ATT GAT GGT ATT $3^{\prime}$ was included in each reaction to determine the expression of the glyceraldehyde-3-phosphate dehydrogenase (Gapdh) for normalization.

\section{Biochemical analyses}

Mice were administered a ketamine-xylazine-acepromazine cocktail intraperitoneally $(0.01 \mathrm{ml} / \mathrm{g}$ of $25 \mathrm{mg} / \mathrm{ml}$ ketamine (Sigma), $0.625 \mathrm{mg} / \mathrm{ml}$ acepromazine (Vetus Animal Health), $3.125 \mathrm{mg} / \mathrm{ml}$ xylazine (Sigma)), and intracardially perfused with $20 \mathrm{ml}$ of $0.9 \%$ PhosphateBuffered Saline. Brains were removed and the hippocampus, cortex, amygdale, and cerebellum were manually dissected from the right hemisphere following an established protocol (Spijker 2011). Dissected brain regions were immediately frozen in liquid nitrogen 
and stored at $-80 \mathrm{C}$ until analysis. Regional brain tissues were homogenized in $500 \mu \mathrm{l}$ of RIPA buffer (1\% NP-40, 0.1\% SDS) (Sigma) containing protease inhibitor (Roche). Protein expression by Western blot was determined using antibodies against human apoE (Calbiochem, 1:2,500 dilution) and $\beta$-actin (1:5,000 dilution). ApoE levels were also measured in plasma using a sandwich ELISA as previously described (Sullivan et al., 2011). Briefly, plasma samples (diluted 3000-fold in PBS-T (1× PBS, pH 7.4, 0.05\% tween-20) and $0.4 \%$ glycine) were loaded into a 96-well plate that had been coated with an anti-apoE antibody (goat anti-human apoE; 1-2000 dilution; Millipore, San Francisco, CA, USA). Following overnight incubation at $4{ }^{\circ} \mathrm{C}$, the samples were removed and the plate washed 3 times with PBS-T prior to incubation with a biotinylated anti-apoE antibody (goat antihuman apoE; 1:5000; Biodesign, Saco, ME, USA) for $1 \mathrm{~h}$ at room temperature. The plates were then washed again 3 times with PBS-T and incubated with streptavidin-HRP for an additional $1 \mathrm{~h}$ at room temperature. The immunocomplex was reacted with TMB substrate and detected using a Spectra MAX 190 (Molecular Devices, Sunnyvale, CA, USA) plate reader. Levels of apoE were normalized to a standard curve generated using recombinant human apoE (Biodesign, Saco, ME, USA). Plasma apoE levels were determined in triplicate and expressed as the amount of apoE per milliliter.

\section{Cholesterol measurements}

Blood was collected retro-orbitally under anesthesia (isofluorane). Approximately $100 \mu \mathrm{l}$ of whole blood was collected into a tube containing $5 \mu \mathrm{l}$ of $0.5 \mathrm{M}$ EDTA. Blood was centrifuged at 5,500 rpm for $10 \mathrm{~min}$ and plasma was removed and stored at $-80^{\circ} \mathrm{C}$ until analysis. Plasma cholesterol was measured using a colorometric assay (Wako) according to manufacturer's instructions. For brain cholesterol analyses, lipids were extracted from cortex and hippocampus homogenates by chloroform:methanol (2:1) extraction. Internal standards were added and the samples were dried and saponified with alcoholic $\mathrm{KOH}$ and extracted into hexane. Samples were derivatized with N,O-Bis(trimethylsilyl)trifluoroacetamide (BSTFA) (Thermo-Scientific Rockford, IL) and cholesterol concentration was measured by capillary column gas chromatography on an Agilent (Santa Clara, CA) gas chromatograph (Model 6890N) with a ZB1701 column (30 m, $0.25 \mathrm{~mm}$ ID, $0.25 \mu \mathrm{m}$ film; Phenomenex, Torrance, CA) and a FID detector. An internal standard (epicoprostanol; Sigma, St. Louis, MO) and an authentic cholesterol standard (Steraloids, Newport, RI) were used for calibration.

\section{Statistical analyses}

Data are expressed as mean \pm standard error. Multiple groups and/or multiple time points were analyzed using multivariate ANOVA or repeated measures ANOVA, using SPSS software (Chicago, IL). To assess potential correlations between apoE and performance in the spatial memory test, two-tailed Pearson correlation calculations were analyzed using GraphPad Prism software (San Diego, CA).

\section{Results}

\section{Physical characteristics and motor function}

No significant differences were observed in body weight, or in adipose tissue, liver, or brain weight (Table 1). There were also no apparent differences in health or physical appearance, and all groups performed similarly with regard to activity levels in an open field, sensorimotor function on a Rotarod, and swim speeds in the water maze (Table 2). 


\section{Novel object recognition is unaffected by $A P O E$ and $L D L R$ genotype}

The Novel object recognition task is based on rodents' natural curiosity and propensity to orient their head toward a novel stimulus (Honey et al., 1998). On the first day of this paradigm, mice were allowed 15 minutes to explore an open arena containing two identical ("Familiar") objects. All groups spent a comparable amount of time exploring each of the two identical objects (Figure 1A). When exposed to a Novel object 24 hours later, all experimental groups - regardless of $A P O E$ or $L D L R$ genotype - spent significantly more time examining the novel object, demonstrating robust object recognition memory (Figure 1B).

\section{ApoE4 is associated with increased anxiety, independent of $L D L R$}

$A P O E$ genotype has been shown to modulate anxiety and anxiety-like behavior in humans and in mice (Raber et al., 2007). To test whether apoE isoform effects on measures of anxiety are dependent on the LDLR, we used the elevated zero maze, a canonical test of anxiety-like behavior (Shepard et al., 1994). There was a significant effect of $A P O E$ genotype on numbers of entries into open areas $(p<0.01$, ANOVA) as well as total time spent in the open areas ( $p<0.001$ respectively by ANOVA) of elevated zero maze (Figure 2A-B). Mice with E4 displayed more anxiety-like behavior than those with E3 or E2. In both the absence and presence of human LDLR, mice with E4 spent less time in the open area of the zero maze $(13.0 \pm 3.6,14.3 \pm 4.2 \%)$ compared to mice with E3 $(18.6 \pm 6.0,19.4 \pm 6.1$ $\%)$ or $\mathrm{E} 2(24.5 \pm 4.5,26.3 \pm 8.9 \%)$ (Figure $2 \mathrm{~B}$ ). This data suggests that the apoE isoforms differentially affect anxiety-like behavior (E4 > E3 $\geq E 2)$ through an LDLR-independent process.

\section{Contextual associative memory is unaffected by APOE or LDLR but cued associative memory is regulated by $A P O E$}

To determine the role of the apoE-LDLR interactions in associative learning and memory, we employed two distinct testing conditions to assess contextual and cued fear conditioning (Figure 3A). First, mice were trained to associate a conditioned stimulus, i.e. a tone, with a mild foot shock (unconditioned stimulus), and thereby come to fear the conditioned stimulus. Trained mice displayed this conditioned fear by freezing - ceasing all movement except for respiration (Maren et al., 2001). There were no group differences in the response to the shock (Figure 3B). All groups demonstrated an increase in freezing across the training session ( $p<0.01$, repeated measures), indicating a learned fear response (Figure 3-C-D). Freezing response during training was not affected by APOE or $L D L R$ and there was no $A P O E \times L D L R$ interaction, although there was a trend towards higher freezing in mice with E4 (APOE effect $p=0.079$, repeated measures).

To test contextual memory, mice were exposed to an identical environment as that encountered during their training. There was no difference in contextual freezing between any of the experimental groups (Figure 3E).

To test cued memory, a Pavlovian-type response heavily regulated by the amygdala, mice were placed in a novel environment (unique compartment shape, floor texture and scent) and exposed to the tone. While $L D L R$ did not alter the cued fear conditioning response and there was no $A P O E \times L D L R$ interaction, there was a significant effect of APOE $(p<0.01$, repeated measures) on freezing in response to the tone. In $\mathrm{LDLR}^{-/-}$mice, the freezing response to the tone was apoE isoform-dependent (E4 > E3 > E2). $\mathrm{LDLR}^{-/}$mice with E4 had a significantly higher freezing response compared to mice with E3 $(p<0.05)$ or E2 $(p<$ $0.01)$, while mice with E3 tended to freeze more than mice with E2 $(p=0.063)$ (Figure $3 \mathrm{~F}$ ). In the presence of human LDLR, mice with E3 or E4 had a similar freezing response to the tone, while mice with E2 had significantly lower freezing levels $(p<0.05$, repeated 
measures) compared to mice with $\mathrm{E} 4$, and there was a trend towards lower freezing levels than in mice with E3 ( $p=0.084)$ (Figure 3G). In summary, there was no effect of APOE, $L D L R$ or $A P O E^{*} L D L R$ interaction for contextual fear conditioning, but a strong effect of $A P O E$ for cued fear conditioning (E4 > E3 > E2) that was independent of $L D L R$ status.

\section{Spatial memory is impaired in the absence of LDLR and in mice with apoE4 and human LDLR}

The Morris water maze is a well-established test to identify spatial learning and/or memory deficits and has been employed in numerous studies of mouse models of neurological disease (Vorhees and Williams, 2006). There were no group differences in swim speeds (Table 2). Therefore, time to reach the platform (latency) was used as performance measure. There were no group differences in ability to reach the platform during the visible platform sessions (Figure 4A-B, "Visible"). Performance improved during the visible and hidden platform sessions (Session effect in each, $p<0.01$ ). These data indicate that there were no genotype differences in cued task learning or spatial learning.

None of the groups showed spatial memory retention in the first probe trial (not shown). However, following additional training, some groups did show spatial memory retention. In the second probe trial (P2), LDLR deficient mice failed to show a preference for the target quadrant, regardless of APOE genotype (Figure 4C) and the majority of $\mathrm{LDLR}^{-/}$mice displayed un-directed search patterns (Figure $4 \mathrm{G}$, top row). However, the presence of human LDLR resulted in significant preference for the target quadrant and clear search strategies in $\mathrm{E} 2$, E3 and $\mathrm{E} 4$ mice $(47.0 \pm 25.8,41.5 \pm 12.2$, and $50.0 \pm 21.6 \%$ time in target quadrant, respectively) (Figure 4D, H top row).

To assess long-term memory retention, we performed a more challenging probe trial 72 hours following the final "Hidden Platform" session. As in the first two probe trials, mice lacking the LDLR failed to show a preference for the target quadrant, regardless of APOE genotype (Figure 4E, G bottom row). Conversely, E2 and E3 mice with human LDLR showed a clear preference for the target quadrant $(42.4 \pm 18.1$ and $40.7 \pm 12.5 \%$ time in target quadrant, respectively) (Figure 4F), and accurate, focused search strategies (Figure $4 \mathrm{H}$, bottom row, shows representative trials). In contrast, E4 mice with human LDLR did not spend significantly more time in the target quadrant than the right and opposite quadrants, suggesting deficiencies in spatial memory. Taken together, both the absence of LDLR (regardless of apoE isoform), as well as the specific combination of E4 and human LDLR, result in deficits in long-term spatial memory.

\section{Plasma Cholesterol is altered by $A P O E^{\star} L D L R$ interaction}

Fasting plasma cholesterol concentrations were drastically altered by both $A P O E$ and $L D L R$ genotype (APOE effect $p<0.001, L D L R$ effect $p<0.001, A P O E \times L D L R$ interaction, $p<$ 0.001 , ANOVA). Human LDLR expression considerably lowered total plasma cholesterol regardless of apoE isoforms (Table 1). Plasma cholesterol was higher in mice with E2 compared to mice with E3, whether or not human LDLR was expressed. However, while plasma cholesterol tended to be lower in E4 mice compared to E3 mice when there was no LDLR, introduction of the human LDLR resulted in significantly higher plasma cholesterol in E4 mice compared to E3 mice (Table 1).

To determine whether the apoE-LDLR interaction influences brain cholesterol content, we performed GC/MS analyses of cholesterol concentrations in the cortex and hippocampus of mice with human LDLR. Hippocampal cholesterol was not affected by APOE genotype (Figure 5, shaded bars). Cholesterol levels in the cortex did not significantly differ by APOE 
genotype. However, there was a trend towards lower cholesterol in human LDLR mice with E4 compared to human LDLR mice with E3 or E2 .

\section{Brain apoE levels are regulated by $A P O E^{\star} L D L R$ interaction; decreased in mice with apoE4 and human LDLR}

In mice with human LDLR, expression of LDLR in the brain was within a physiological range comparable to that of WT mice, ranging between 30.3 to $145.8 \%$ of wild type mice (WT). There was no significant difference in human LDLR expression between E2, E3 and E4 mice $(88.5 \pm 17.2,92.1 \pm 10.7$, and $87.3 \pm 19.6 \%$ of WT, respectively) (Figure 6A).

To determine the regulatory effects of human LDLR expression on the various apoE isoforms, we performed western blot analyses of plasma and regional brain apoE concentrations. Plasma apoE levels were modulated by APOE genotype as well as markedly lowered by LDLR expression (LDLR effect $p<0.001$, APOE effect $p<0.01$ by ANOVA). In the absence of LDLR, plasma apoE concentrations did not differ by APOE genotype (Figure 6B, left). However, when human LDLR was present, plasma apoE concentrations were significantly higher in mice with E2 $(20.3 \pm 1.5 \mu \mathrm{g} / \mathrm{ml})$ than E3 or E4 $(7.0 \pm 0.9$ and $5.9 \pm 0.5 \mu \mathrm{g} / \mathrm{ml}$, respectively) (Figure 6B-C).

In the brain, there was a significant effect of $A P O E, L D L R$ and a significant $A P O E \times L D L R$ interaction when all regions were analyzed together $(p<0.01$, repeated measures). In most brain regions examined, $A P O E$ genotype had no effect on levels of apoE in the absence of LDLR. LDLR deficient mice with E2, E3 or E4 had similar levels of apoE in the cortex, hippocampus and amygdala (Figure 6E-G, left side). However, in the cerebellum of $\mathrm{LDLR}^{-/}$mice, levels of apoE were significantly greater in E2 than E3 or E4 mice (Figure $6 \mathrm{D}-\mathrm{H}$, left side).

In contrast, a clear pattern (E2 $>\mathrm{E} 3>\mathrm{E} 4)$ emerged in all brain regions measured in mice with human LDLR (APOE*LDLR effect, all regions $p<0.01)$. In human LDLR mice, apoE levels in the hippocampus and amygdala were higher in E2 than E4 mice, and apoE levels in cortex and cerebellum were higher in E2 than in either E3 or E4 (Figure 6E-H, right side). Together, these data suggest that the LDLR regulates brain apoE levels in an isoformdependent manner, and that regional variations in apoE level may also exist.

Based on these findings, we inquired how levels of apoE differed in the presence of human LDLR compared to mouse LDLR, as the human apoE Targeted Replacement (TR) mice are a commonly used model in the AD and CVD fields. For comparison, western blot analysis of plasma and regional brain apoE were performed in parallel for E2, E3 and E4 mice with the endogenous mouse LDLR. Similar to previously published reports (Riddell et al., 2008, Sullivan et al., 2011), we observed significantly elevated plasma apoE levels in TR mice with human E2 compared to those with E3 and E4 ( $<<0.01$ ), as well as a significant genotype effect on apoE levels when all regions were analyzed together $(\mathrm{p}<0.01$, Repeated Measures) as well as in the cortex ( $\mathrm{p}<0.05$, ANOVA) (Supplemental Figure 1).

\section{Hippocampus apoE correlates with long-term spatial memory retention}

Spatial memory retention was impaired in mice lacking LDLR when tested at both 24 and 72 hours post-training, regardless of APOE genotype. When human LDLR was introduced, mice with E2 and E3 demonstrated robust spatial memory retention at both 24 and 72 hours. While mice with human LDLR and E4 performed similar to their E2 and E3 counterparts in the 24 hour spatial memory test, they showed impaired long term memory retention during the 72 hour test. Based on this genotype difference, we next analyzed the relationship 
between long term memory retention and apoE levels in the hippocampus - a brain region critical for performance on this task.

In mice with human LDLR, better performance in the 72 hour probe trial of the water maze was associated with higher levels of hippocampal apoE (Figure 7B). Hippocampal apoE levels were positively correlated with the percent time spent in the target quadrant in the probe trial in human LDLR mice with E2 $\left(r^{2}=0.695, p<0.05\right.$, Pearson correlation $)$ and E3 $\left(r^{2}=0.695, p<0.05\right.$ and $r^{2}=0.884, p<0.01$, Pearson correlation). While the overall trend was similar, the correlation did not reach significance in human LDLR mice with E4 $\left(r^{2}=\right.$ $0.468, p=0.089$, Pearson correlation). When the data of human LDLR mice with all three apoE isoforms were analyzed together, there was a strong positive correlation between hippocampal apoE levels and the percent time spent in the target quadrant $\left(r^{2}=0.722, p<\right.$ 0.001 , Pearson correlation). This positive correlation was not present in LDLR deficient mice, irrespective of APOE genotype (all LDLR ${ }^{-/}$groups combined, $r^{2}=0.0065, p=$ 0.7502 , Pearson correlation) (Figure 7A). Additionally, no group showed a correlation between water maze performance and apoE levels in the cortex, amygdale or cerebellum, nor did apoE levels in any of these brain regions correlate with other behavioral tests (object recognition, anxiety, fear conditioning, or spatial memory retention in the water maze probe trials). These data suggest a role for the LDLR in regulating hippocampal apoE levels and long-term retention of spatial memory.

\section{Discussion}

In this study, we examined whether the interaction between apoE and the LDLR results in apoE isoform-dependent cognitive and biological effects. We show that both anxiety-like behavior and cued associative memory are strongly influenced by APOE genotype in both the absence and presence of human LDLR, suggesting that these processes occur via an LDLR independent mechanism. Conversely, the interaction between apoE and LDLR appears especially important in the regulation of plasma and brain apoE levels and spatial memory retention in the water maze. Particularly, both the lack of LDLR and the specific interaction between apoE4 and the LDLR were associated with impairments in the retention of long-term spatial memory. Furthermore, in mice with human LDLR, hippocampal apoE levels correlated with long-term spatial memory retention.

Together with epidemiological studies (Cheng et al., 2005, Gopalraj et al., 2005, Retz et al., 2001, Vermissen et al., 2011, Zou et al., 2008), these data point toward a functional interaction between apoE and LDLR as a potential mechanism to explain the apoE isoformdependent disease risks associated with both CVD and AD. While numerous lipoprotein receptors have been shown to interact with apoE in the brain, the LDLR is the only receptor in its class of receptors to show varying binding affinities for the three apoE isoforms (E4 > E3 >> E2) (Innerarity et al., 1983, Yamamoto et al., 2008). Interestingly, the increased CVD risk normally associated with APOE4 genotype disappears in Familial Hypercholesterolemia (FH) patients, who lack functioning LDLR (Vermissen et al., 2011). While this may simply be due to the effects of APOE4 being overwhelmed by severely elevated cholesterol levels in FH patients, an alternative explanation is that the harmful cardiovascular effect of E4 relies on a functional interaction with LDLR. In mice, the introduction of human LDLR results in apoE isoform-dependent differences in diet-induced atherosclerotic plaque development (Malloy et al., 2004). In addition, the development of atherosclerosis is accelerated in mice when human LDLR and E4 were combined in the background of diabetes (Johnson et al., 2013). It has been proposed that these harmful effects might originate from a reduction in the available pool of functional E4 due to "trapping" by the LDLR (Altenburg et al., 2008, Malloy et al., 2004), but regardless of the mechanism, the 
interaction between LDLR and E4 appears to be an important disease modifying mechanism in the setting of CVD.

While apoE has been the subject of countless studies over the past few decades, the study of its primary receptor in the periphery, the LDLR, has been relatively understudied in the brain. Still, several important genetic studies have implicated the LDLR - and the apoELDLR interaction - as a disease modifying mechanism in AD. Gopalraj et al. (2005) showed that a specific LDLR haplotype was associated with reduced AD risk, while Zou et al. (2008) demonstrated that a SNP in LDLR exon 12 was associated with increased AD risk in men. Furthermore, studies by Retz et al. (2001) and Cheng et al. (2005) demonstrated an increase in AD risk when polymorphisms in LDLR exon 8 and exon 13 were present in conjunction with an $\varepsilon 4$ allele. These studies imply that a functional interaction between apoE and LDLR may modify AD risk in an apoE isoform-dependent manner. The apoELDLR interaction may play an indirect role in the context of $\mathrm{AD}$, such as through regulation of vascular function. Vascular brain injury may predict cognitive outcome better than amyloid $\beta$ deposition (Marchant et al., 2013). In addition, several vascular risk factors, including apoE-LDLR system, are shared by AD and CVD (Altman et al., 2010).

The apoE-LDLR interaction may also play a more direct role through the modulation of amyloid clearance and/or deposition. Several intriguing studies have shed some light onto the potential pathophysiological pathways by which LDLR may contribute to AD. In cell culture, overexpression of APP led to increased expression of LDLR and altered receptor localization (Abisambra et al., 2010). Varying results in amyloid deposition have been shown in AD mouse models lacking the LDLR, with one study showing that amyloid deposition was enhanced on a LDLR null background (Katsouri et al., 2011), while in another study LDLR deficiency had no effect on brain A $\beta$ levels (Fryer et al., 2005). On the other hand, Kim et al. (2009) showed that LDLR over-expression reduced brain apoE levels and reduced amyloid $\beta$ aggregation, while further work from the same laboratory showed that LDLR over-expression in the brain increased the rate of brain-to-blood clearance of both exogenously administered and endogenous $A \beta$ (Castellano et al., 2012). These studies, in which LDLR over-expression increases $A \beta$ clearance, point to upregulation of LDLR in the brain as a potential therapeutic strategy for AD. However, whether this strategy is beneficial in the presence of all apoE isoforms remains unclear. Our previous work in the context of CVD suggests that lipoprotein metabolism in the periphery - and possibly in the brain as well - may be negatively affected by this strategy in the presence of apoE4 (Altenburg et al., 2007, Malloy et al., 2004, Johnson et al., 2013).

While human apoE targeted replacement (TR) mice are an invaluable research model, the type III Hyperlipoproteinemia (HLP) and grossly elevated plasma apoE concentrations in TR mice (and knock-in mice) with E2 are significant confounders (Mahley et al., 1999). This is particularly significant in the context of lipid, inflammatory and other vascular contributions in CVD and dementia. Many researchers avoid these confounding issues by excluding E2 mice from their studies, a regrettable situation given the important protective role of E2 in AD. It has been suggested that the type III HLP observed in E2 mice might be a result of sub-par binding of E2 to murine apoE receptors (Sullivan98). When murine LDLR is replaced with human LDLR, as in this study and others (Knouff et al. 2001), this issue is resolved as plasma lipids return to normal physiological levels, allowing for study of the $\varepsilon 2$ allele in a physiologically relevant context.

Body mass index, obesity, insulin, and prevalence of Metabolic Syndrome, have all been associated with APOE genotype (Elousa et al., 2003, Oh et al., 2001, Marques-Vidal et al., 2003, Sima et al., 2007, Volcik et al., 2006). Additionally, LDLR polymorphisms have been associated with varying degrees of body mass and adipose tissue distribution (Mattevi et al., 
2000), and the insulin receptor (IR) has been shown to co-associate with LDLR and affect its function (Ramakrishnan et al., 2012). The effects of apoE isoform and LDLR family receptors on adipose tissue mass and function have been studied in both human tissue (Huang et al., 2011) and in mice (Arbones-Mainar et al., 2008, Arbones-Mainar et al., 2010, Karraginades et al., 2008, Schreyer et al., 2002). In this study, we did not observe differences in body weight or adipose tissue mass based on apoE isoform or the presence of LDLR. However, these data do not rule out potential effects of $A P O E$ genotype on adipose tissue function, particularly in the context of metabolic challenges such as obesity or diabetes. In fact, several studies show that E4 exacerbates the severity of cognitive dysfunction and risk of dementia in patients with type 2 diabetes (Dore et al., 2003, Irie et al., 2008, Kota et al., 2012, Peila et al., 2002).

Anxiety symptoms occur in 50-75\% of AD patients (Gustavson et al., 2004), is more profound in $\varepsilon 4$ than $\varepsilon 3$ homozygote men with probable $\mathrm{AD}$ (Robertson et al., 2005), and anxiety is inversely related to cognitive function (Porter et al., 2003), particularly in E4 homozygotes (Stonnington et al., 2011). Unlike spatial memory, anxiety-like behavior was unaffected by LDLR in this study. Instead, anxiety was strongly determined by APOE genotype in both the presence and absence of LDLR. In the elevated zero-maze, a test of anxiety-like behavior, mice with E4 displayed significantly more anxiety than those with E3 or E2. These data suggest that this strong APOE genotype effect on anxiety (E4 > E3 > E2) occurs through an LDLR-independent mechanism.

Pavlovian fear conditioning is a versatile and well-understood method of assessing associative learning (Maren, 2001). Contextual fear conditioning is considered to involve complex polymodal processing, and to be hippocampus and amygdala-dependent, while fear conditioning to a modality-specific cue (e.g. a tone) is considered to be hippocampusindependent (Debiec et al., 2004). APOE genotype has been shown to affect fear conditioning in mice (Kornecook et al., 2010, Olsen et al., 2012). In this study, we did not observe an effect of $A P O E, L D L R$ or an $A P O E \times L D L R$ interaction for contextual fear conditioning. Conversely, we observed a strong effect of $A P O E$ genotype on cued memory. Similar to anxiety-like behavior in the elevated zero maze, cued fear conditioning showed an $A P O E$ effect (E4 > E3 > E2) that was similar in the presence and absence of human LDLR. Interestingly, both of these neuropsychological processes strongly rely on the amygdala. Although the pattern and levels of apoE in the amygdala were similar to the other brain regions measured, these data imply that the apoE isoforms may exert unique effects in this particular brain region through an LDLR-independent mechanism. These data may suggest that other brain regions may play a role in modulating these effects, or more likely that - at least in regard to the amygdale - the apoE isoform present is more important than actual apoE levels. Alternatively, the apoE isoforms may regulate anxiety and fear learning through neuroendocrine pathways (Raber, 2007). Previously, APOE has been implicated in the risk and severity of post-traumatic stress disorder (PTSD) (Freeman et al., 2005, Olsen et al., 2012, Kim et al., 2013). As apoE is highly synthesized in the steroidogenic tissues like the adrenal gland (Blue et al., 1983, Driscoll and Getz, 1984, Elshourbagy et al., 1985) and in certain conditions low cortisol concentrations are associated with higher risk of PTSD (Meewisse et al., 2007), these neuroendocrine pathways may be the critical link between various disorders of fear and anxiety and $A P O E$ genotype.

While cued associative memory and anxiety-like behavior were influenced by APOE genotype in an LDLR-independent manner, spatial memory was heavily influenced by LDLR expression as well as by an APOE $\times L D L R$ interaction. To assess hippocampusdependent spatial learning and memory, we employed the Morris water maze (WM) (Vorhees et al., 2006). In the water maze, the absence of LDLR resulted in major deficits in spatial memory. This supports a previous study that showed the importance of LDLR in 
spatial memory retention (Mulder et al., 2004). Here we extend these findings to show that this effect is independent of $A P O E$ genotype. Importantly, introducing human LDLR in the presence of E2 or E3 completely ameliorated the spatial memory deficits observed in $\mathrm{LDLR}^{-/-}$mice. However, in the presence of E4, introducing human LDLR only partially ameliorated these deficits; E4 mice with human LDLR demonstrated memory retention at 24 hours, but not 72 hours, post-training. These data suggest that the pathways that underlie spatial memory - at least in regards to specific cognitive processes tested by the water maze - require functional interaction between apoE and the LDLR. Furthermore, the interaction between E4 and LDLR resulted in deficiencies that were not present in E2 and E3, specifically in the context of long term memory retention ( 72 hours). This may be due to an inability of the LDLR to rescue the impairments in long-term spatial memory by interacting with E4 as it is able to do with E2 and E3. Conversely, these memory deficits may arise through a biological mechanism that is unique to the E4-LDLR interaction. Perhaps related, studies show that, compared to E3 mice, E4 mice have lower baseline long term potentiation (LTP) (Trommer et al., 2004), increased LTP inhibition by Amyloid $\beta 42$ (Trommer et al., 2005), and suppression of LTP enhancement by Reelin-induction (Chen et al., 2010).

Neurons require substantial amounts of cholesterol to maintain their prolific dendritic extensions (Yu et al., 2010), and astrocytes provide neurons with exogenous cholesterol in the form of apoE-containing high density lipoprotein (HDL)-like particles (Boyles et al., 1985, Boyles et al., 1989, Yu et al., 2010). The trafficking of these HDL-like particles in the brain is likely affected by interaction of apoE with the LDLR, as it is in the periphery. To examine whether variability in this interaction based on apoE isoform could lead to differences in brain cholesterol concentrations, we measured cholesterol in the cortex and hippocampus of human apoE mice with human LDLR. Neither cortical nor hippocampal cholesterol levels o were significantly affected by APOE genotype, although there was a trend towards lower cortical cholesterol in human LDLR mice with E4. This may suggest that cortical cholesterol is more sensitive to apoE-LDLR mediated processes, or hippocampal cholesterol levels may be more tightly controlled and/or managed by additional regulatory mechanisms. However, brain cholesterol concentrations did not correlate with any of the behavioral outcomes measured in this study.

Conflicting results concerning the role of apoE in learning and memory have been demonstrated in apoE deficient mice. Some studies show no significant cognitive impairments compared to either wild type or human apoE3 expressing mice (Raber et al., 1998, Grootendorst et al., 2005, Hartman et al., 2001, van Meer et al., 2007), while others show severe learning and memory deficits (Gordon et al., 1995, Oitzl et al., 1997, Veinbergs et al., 1999). On the other hand, numerous studies have examined how the apoE isoforms differentially impact the expression and function of apoE in humans and in mice (Betrand et al., 1995, Beffert et al., 1999, Fryer et al., 2005, Fukomoto et al., 2003, Glockner et al., 2002, Poirer et al., 2005, Ramaswamy et al., 2005, Riddell et al., 2008, Sullivan et al., 2004). Still, it remains unclear exactly how apoE levels are altered during normal and pathological aging, and if alterations in concentrations of brain apoE could affect pathways of learning and memory that rely on apoE-mediated lipid trafficking or signaling (Yu et al., 2010). Interestingly, apoE levels in E2 mice with human LDLR did not differ in any brain region from apoE levels in any of the $\mathrm{LDLR}^{-/}$mice. This may reflect an inability of the LDLR to effectively regulate E2 levels in the brain, or a preference for other receptors that play critical roles in the brain such as LRP or VLDLR. In this regard, the brain may differ from the periphery, where the presence of human LDLR lowers plasma apoE in E2 mice to levels 5-fold lower than $\mathrm{LDLR}^{-/-}$mice or E2 mice with endogenous mouse LDLR.

Conversely, apoE levels in E4 mice with human LDLR were significantly lower than those of all $\mathrm{LDLR}^{-/-}$mice in the four brain regions analyzed. It has been suggested that low levels of brain apoE exhibited by E4-carrying patients may directly contribute to the progression of 
memory loss (Riddell et al., 2008). In this study, we limited our analyses of brain apoE to the insoluble (detergent-soluble) fraction as this preparation more accurately reflects the levels of lipidated apoE. The lipidation status of apoE directly affects its structure and function (Hauser et al., 2011), including its interaction with amyloid $\beta$ (Fan et al., 2009, LaDu et al., 1994, Tokuda et al., 2000). In fact, increasing the levels and lipidation of apoE is a therapeutic mechanism attributed to the class of peroxisome proliferator-activated receptor- $\gamma$, retinoid $\times$ receptor, and liver $\times$ receptor agonists that have shown recent promise (Cao et al., 2007, Cramer et al., 2012, Lefterov et al., 2007, Terwel et al., 2011). Seemingly in conflict, several studies have shown that the opposite approach of lowering brain apoE levels may also be beneficial. Kim et al. (2011) demonstrated that lower brain apoE levels in hemizygous human apoE mice were associated with decreased amyloid deposition.

Similarly, reducing apoE levels using Cre-mediated gene excision resulted in lower brain A $\beta$ levels (Bien-Ly et al., 2012). Furthermore, over-expression of LDLR - while increasing clearance of $A \beta$ - results in decreased brain apoE concentrations (Kim et al., 2009), although this clearance may occur through an apoE-independent pathway (Basak et al., 2012). Along these lines, others have suggested that increasing levels of brain apoE may be harmful rather than beneficial in E4+ patients, due to toxic effects of the apoE4 protein itself (Mahley et al., 2006). Perhaps another important distinction in regards to $A \beta$ clearance is where the apoE is located, i.e. the synapse. Tai et al. (2013) recently showed that in soluble preparations of human synaptosomes, levels of apoE/A $\beta$ complex were lower in $\mathrm{AD}$ patients compared to controls, as well as lower in E4+ compared to E4- patients with AD. It is unknown whether the LDLR affects apoE levels and apoE-mediated $A \beta$ clearance at the synapse, and further studies examining these mechanisms are warranted.

We observed a strong positive correlation between hippocampus apoE levels and performance in the water maze. Importantly, this correlation was only observed in mice with human LDLR. Taken together, these data suggest that: 1) LDLR regulates hippocampus apoE levels in an isoform dependent manner, and 2) in regards to the retention of long term spatial memory, total apoE levels may be more important than the specific isoform present. However, due to the correlative nature of this study, the possibility remains that the isoform of apoE present, rather than the overall level, is the key determinant of spatial memory retention. To our knowledge, this is the first study to demonstrate an association between hippocampus human apoE levels and cognitive performance in a test of long term spatial memory.

In this study, we focused our analyses on hemizygous human LDLR (h/-) mice. Expression of human LDLR in these mice is limited to a range of $16-205 \%$, with a mean of $99 \%$, compared to murine LDLR in wild-type mice. It should also be noted that this study only involved female mice, and that apoE isoform specific sex differences in behavior have been previously shown (Raber et al., 1998, Raber et al., 2000). Regardless, a benefit of this model is that future studies can examine effects of hyper-physiological increases in human LDLR expression using homozygous human LDLR mice $(\mathrm{h} / \mathrm{h})$. Such studies would provide valuable insight into the potential effects of various therapies aimed at increasing LDLR expression - such as lowering LDL cholesterol in individuals at risk for CVD or increasing $\mathrm{A} \beta$ clearance in $\mathrm{AD}$ patients. Of particular interest is the class of cholesterol lowering drugs designed to inhibit PCSK9, an enzyme which enhances the degradation of the LDLR. Given the harmful effects of increasing LDLR expression in the presence of apoE4 in a mouse model of CVD (Altenburg et al., 2007, Johnson et al., 2013, Malloy et al., 2004), as well as the E4-associated effects on spatial memory observed in this study, additional caution may be needed when considering E4+ patients.

In summary, both anxiety-like behavior and cued associative memory are strongly influenced by APOE genotype, but these processes appear to occur via an LDLR- 
independent mechanism. Conversely, plasma and brain apoE levels, cortical cholesterol, and spatial memory are all regulated by isoform specific interactions between apoE and LDLR. Interestingly, both the lack of LDLR and the specific interaction between E4 and the LDLR were associated with impairments in the retention of long term spatial memory. Finally, levels of hippocampus apoE correlate with long term spatial memory retention in mice with human LDLR. Future studies are warranted to address the precise biological mechanisms by which the apoE-LDLR interaction regulates brain apoE levels in an isoform dependent manner, how varying apoE levels affect spatial memory, as well as examine the potential apoE isoform-specific results of increasing LDLR expression as a therapeutic strategy.

\section{Supplementary Material}

Refer to Web version on PubMed Central for supplementary material.

\section{Acknowledgments}

The authors would like to thank Erin Bidiman, Massarra Eiwaz, Jackie Lanz, Tessa Marzulla, Blair Stewart, Dawn Cote and Dr. Damian Zuloaga for their invaluable assistance. This work was supported by National Institute of Environmental Health Sciences grant T32-ES07060 and the development account of JR. Its contents are solely the responsibility of the authors and do not necessarily represent the official views of the National Institutes of Health. LAJ was also supported by the National Institute of Health grant T32-HL094294, the Collins Medical Trust and the Oregon Tax Check-off Program for Alzheimer's Research administered by the Layton Aging \& Alzheimer's Disease Center, Oregon Health \& Science University.

\section{References}

1. Abisambra JF, Fiorelli T, Padmanabhan J, Neame P, Wefes I, Potter H. LDLR expression and localization are altered in mouse and human cell culture models of Alzheimer's disease. PLoS One. Jan 1.2010 5(1):e8556. doi: 10.1371/journal.pone.0008556. [PubMed: 20049331]

2. Altenburg M, Johnson L, Wilder J, Maeda N. Apolipoprotein E4 in macrophages enhances atherogenesis in a low density lipoprotein receptor-dependent manner. J Biol Chem. Mar 16; 2007 282(11):7817-24. doi: 10.1074/jbc.M610712200. [PubMed: 17234631]

3. Altenburg M, Arbones-Mainar J, Johnson L, Wilder J, Maeda N. Human LDL receptor enhances sequestration of ApoE4 and VLDL remnants on the surface of hepatocytes but not their internalization in mice. Arterioscler Thromb Vasc Biol. Jun; 2008 28(6):1104-10. [PubMed: 18369154]

4. Altman R, Rutledge JC. The vascular contribution to Alzheimer's disease. Clin Sci (Lond). Aug 5; 2010 119(10):407-21. doi: 10.1161/ATVBAHA.108.164863. [PubMed: 20684749]

5. Arbones-Mainar JM, Johnson LA, Altenburg MK, Maeda N. Differential modulation of dietinduced obesity and adipocyte functionality by human apolipoprotein E3 and E4 in mice. Int J Obes (Lond). Oct; 2008 32(10):1595-605. doi: 10.1038/ijo.2008.143. [PubMed: 18725890]

6. Arbones-Mainar JM, Johnson LA, Altenburg MK, Kim HS, Maeda N. Impaired adipogenic response to thiazolidinediones in mice expressing human apolipoproteinE4. FASEB J. Oct; 2010 24(10):3809-18. doi: 10.1096/fj.10-159517. [PubMed: 20501792]

7. Basak JM, Verghese PB, Yoon H, Kim J, Holtzman DM. Low-density lipoprotein receptor represents an apolipoprotein E-independent pathway of $\mathrm{A} \beta$ uptake and degradation by astrocytes. $\mathrm{J}$ Biol Chem. Apr 20; 2012 287(17):13959-71. doi: 10.1074/jbc.M111.288746. [PubMed: 22383525]

8. Beffert U, Cohn JS, Petit-Turcotte C, Tremblay, et al. Apolipoprotein E and beta-amyloid levels in the hippocampus and frontal cortex of Alzheimer's disease subjects are disease-related and apolipoprotein E genotype dependent. Brain Res. Oct 2; 1999 843(1-2):87-94. doi: 10.1016/ S0006-8993(99)01894-6. [PubMed: 10528114]

9. Beffert U, Stolt PC, Herz J. Functions of lipoprotein receptors in neurons. J Lipid Res. Mar; 2004 45(3):403-9. doi: 10.1194/jlr.R300017-JLR200. [PubMed: 14657206]

10. Betrand P, Poirier J, Oda T, Finch CE, Pasinetti GM. Association of apolipoprotein E genotype with brain levels of apolipoprotein $\mathrm{E}$ and apolipoprotein $\mathrm{J}$ (clusterin) in Alzheimer disease. Brain 
Res Mol Brain Res. Oct; 1995 33(1):174-8. doi: 10.1016/0169-328X(95)00097-C. [PubMed: 8774959]

11. Bien-Ly N, Gillespie AK, Walker D, Yoon SY, Huang Y. Reducing human apolipoprotein E levels attenuates age-dependent $\mathrm{A} \beta$ accumulation in mutant human amyloid precursor protein transgenic mice. J Neurosci. Apr 4; 2012 32(14):4803-11. doi: 10.1523/JNEUROSCI.0033-12.2012. [PubMed: 22492035]

12. Blue ML, Williams DL, Zucker S, Khan SA, Blum CB. Apolipoprotein E synthesis in human kidney, adrenal gland, and liver. Proc Natl Acad Sci U S A. Jan; 1983 80(1):283-7. [PubMed: 6572003]

13. Boyles JK, Zoellner CD, Anderson LJ, et al. A role for apolipoprotein E, apolipoprotein AI, and low density lipoprotein receptors in cholesterol transport during regeneration and remyelination of the rat sciatic nerve. J. Clin. Invest. 1989; 83:1015-1031. doi: 10.1172/JCI113943. [PubMed: 2493483]

14. Boyles JK, Pitas RE, Wilson E, Mahley RW, Taylor JM. Apolipoprotein E associated with astrocytic glia of the central nervous system and with nonmyelinating glia of the peripheral nervous system. J. Clin. Invest. 1985; 76:1501-1513. doi: 10.1172/JCI112130. [PubMed: 3932467]

15. Broadbent NJ, Gaskin S, Squire LR, Clark RE. Object recognition memory and the rodent hippocampus. Learn Mem. Dec 22; 2009 17(1):5-11. doi: 10.1101/lm.1650110. [PubMed: 20028732]

16. Cao G, Bales KR, DeMattos RB, Paul SM. Liver X receptor-mediated gene regulation and cholesterol homeostasis in brain: relevance to Alzheimer's disease therapeutics. Curr Alzheimer Res. Apr; 2007 4(2):179-84. doi: 10.2174/156720507780362173. [PubMed: 17430244]

17. Castellano JM, Deane R, Gottesdiener AJ, Verghese PB, Stewart FR, West T, Paoletti AC, Kasper TR, DeMattos RB, Zlokovic BV, Holtzman DM. Low-density lipoprotein receptor overexpression enhances the rate of brain-to-blood $A \beta$ clearance in a mouse model of $\beta$-amyloidosis. Proc Natl Acad Sci U S A. Sep 18; 2012 109(38):15502-7. doi: 10.1073/pnas.1206446109. [PubMed: 22927427]

18. Chen Y, Durakoglugil MS, Xian X, Herz J. ApoE4 reduces glutamate receptor function and synaptic plasticity by selectively impairing ApoE receptor recycling. Proc Natl Acad Sci U S A. Jun 29; 2010 107(26):12011-6. doi: 10.1073/pnas.0914984107. [PubMed: 20547867]

19. Cheng D, Huang R, Lanham IS, Cathcart HM, Howard M, Corder EH, Poduslo SE. Functional interaction between APOE4 and LDL receptor isoforms in Alzheimer's disease. J Med Genet. Feb; 2005 42(2):129-31. doi: 10.1136/jmg.2004.024968. [PubMed: 15689450]

20. Cramer PE, Cirrito JR, Wesson DW, Lee CY, Karlo JC, Zinn AE, Casali BT, Restivo JL, Goebel WD, James MJ, Brunden KR, Wilson DA, Landreth GE. ApoE-directed therapeutics rapidly clear $\beta$-amyloid and reverse deficits in AD mouse models. Science. Mar 23; 2012 335(6075):1503-6. doi: 10.1126/science.1217697. [PubMed: 22323736]

21. Debiec J, Ledoux JE. Disruption of reconsolidation but not consolidation of auditory fear conditioning by noradrenergic blockade in the amygdala. Neuroscience. 2004; 129(2):267-72. doi: 10.1016/j.neuroscience.2004.08.018. [PubMed: 15501585]

22. Dore GA, Elias MF, Robbins MA, Elias PK, Nagy Z. Presence of the APOE epsilon4 allele modifies the relationship between type 2 diabetes and cognitive performance: the Maine-Syracuse Study. Diabetologia. Dec; 2009 52(12):2551-60. doi: 10.1007/s00125-009-1497-2. [PubMed: 19693485]

23. Driscoll DM, Getz GS. Extrahepatic synthesis of apolipoprotein E. J Lipid Res. Dec 1; 1984 25(12):1368-79. [PubMed: 6530593]

24. Elshourbagy NA, Liao WS, Mahley RW, Taylor JM. Apolipoprotein E mRNA is abundant in the brain and adrenals, as well as in the liver, and is present in other peripheral tissues of rats and marmosets. Proc Natl Acad Sci U S A. Jan; 1985 82(1):203-7. [PubMed: 3918303]

25. Elosua R, Demissie S, Cupples LA, Meigs JB, Wilson PW, Schaefer EJ, Corella D, Ordovas JM. Obesity modulates the association among APOE genotype, insulin, and glucose in men. Obes Res. 2003; 11:1502-1508. doi: 10.1038/oby.2003.201. [PubMed: 14694215] 
26. Fan J, Donkin J, Wellington C. Greasing the wheels of A $\beta$ clearance in Alzheimer's disease: the role of lipids and apolipoprotein E. Biofactors. 2009; 35(3):239-248. [PubMed: 19472365]

27. Freeman T, Roca V, Guggenheim F, Kimbrell T, Griffin WS. Neuropsychiatric associations of apolipoprotein $\mathrm{E}$ alleles in subjects with combat-related posttraumatic stress disorder. $\mathrm{J}$ Neuropsychiatry Clin Neurosci. 2005; 17(4):541-3. Fall doi: 10.1176/appi.neuropsych.17.4.541. [PubMed: 16387995]

28. Fryer JD, Simmons K, Parsadanian M, Bales KR, Paul SM, Sullivan PM, Holtzman DM. Human apolipoprotein E4 alters the amyloid-beta 40:42 ratio and promotes the formation of cerebral amyloid angiopathy in an amyloid precursor protein transgenic model. J Neurosci. Mar 16; 2005 25(11):2803-10. doi: 10.1523/JNEUROSCI.5170-04.2005. [PubMed: 15772340]

29. Fukumoto H, Ingelsson M, Gårevik N, Wahlund LO, Nukina N, Yaguchi Y, Shibata M, Hyman BT, Rebeck GW, Irizarry MC. APOE epsilon 3/ epsilon 4 heterozygotes have an elevated proportion of apolipoprotein E4 in cerebrospinal fluid relative to plasma, independent of Alzheimer's disease diagnosis. Exp Neurol. Sep; 2003 183(1):249-53. doi: 10.1016/ S0014-4886(03)00088-8. [PubMed: 12957508]

30. Gamba P, Testa G, Sottero B, Gargiulo S, Poli G. Leonarduzzi. The link between altered cholesterol metabolism and Alzheimer's disease. Ann N Y Acad Sci. Jul.2012 1259:54-64. doi: 10.1111/j.1749-6632.2012.06513.x. [PubMed: 22758637]

31. Glöckner F, Meske V, Ohm TG. Genotype-related differences of hippocampus apolipoprotein E levels only in early stages of neuropathological changes in Alzheimer's disease. Neuroscience. 2002; 114(4):1103-14. doi: 10.1016/S0306-4522(02)00178-1. [PubMed: 12379263]

32. Go GW, Mani A. Low-density lipoprotein receptor (LDLR) family orchestrates cholesterol homeostasis. Yale J Biol Med. Mar; 2012 85(1):19-28. [PubMed: 22461740]

33. Gopalraj RK, Zhu H, Kelly JF, Mendiondo M, Pulliam JF, Bennett DA, Estus S. Genetic association of low density lipoprotein receptor and Alzheimer's disease. Neurobiol Aging. Jan; 2005 26(1):1-7. 10. doi: 1016/j.neurobiolaging.2004.09.001. [PubMed: 15585340]

34. Gordon I, Grauer E, Genis I, Sehayek E, Michaelson DM. Memory deficits and cholinergic impairments in apolipoprotein E-deficient mice. Neurosci Lett. Oct 13; 1995 199(1):1-4. doi: 10.1016/0304-3940(95)12006-P. [PubMed: 8584214]

35. Grootendorst J, Bour A, Vogel E, Kelche C, Sullivan PM, Dodart JC, Bales K, Mathis C. Human apoE targeted replacement mouse lines: h-apoE4 and h-apoE3 mice differ on spatial memory performance and avoidance behavior. Behav Brain Res. Apr 15; 2005 159(1):1-14. doi: 10.1016/ j.bbr.2004.09.019. [PubMed: 15794991]

36. Gustavson, A.; Cummings, J. Assessment and treatment of neuropsychiatric symptoms in Alzheimer's disease.. In: Richter, RW.; Richer, BZ., editors. Current Clinical Neurology, Alzheimer's Disease; A Physician's Guide for Pratical Management. Humana Press Totowa; Totowa, NJ, USA: 2004. p. 371-385.

37. Hartman RE, Wozniak DF, Nardi A, Olney JW, Sartorius L, Holtzman DM. Behavioral phenotyping of GFAP-apoE3 and -apoE4 transgenic mice: apoE4 mice show profound working memory impairments in the absence of Alzheimer's-like neuropathology. Exp Neurol. Aug; 2001 170(2):326-44. [PubMed: 11476599]

38. Hauser PS, Narayanaswami V, Ryan RO. Apolipoprotein E: from lipid transport to neurobiology. Prog Lipid Res. Jan; 2011 50(1):62-74. doi: 10.1016/j.plipres.2010.09.001. [PubMed: 20854843]

39. Herz J, Chen Y. Reelin, lipoprotein receptors and synaptic plasticity. Nat Rev Neurosci. Nov; 2006 7(11):850-9. doi:10.1038/nrn2009. [PubMed: 17053810]

40. Honey RC, Watt A, Good M. Hippocampus lesions disrupt an associative mismatch process. J Neurosci. Mar 15; 1998 18(6):2226-30. [PubMed: 9482806]

41. Huang ZH, Maeda N, Mazzone T. Expression of the human apoE2 isoform in adipocytes: altered cellular processing and impaired adipocyte lipogenesis. J Lipid Res. Sep; 2011 52(9):1733-41. doi: 10.1194/jlr.M017160. [PubMed: 21743035]

42. Innerarity TL, Pitas RE, Mahley RW. Binding of arginine-rich (E) apoprotein after recombination with phospholipid vesicles to the low density lipoprotein receptors of fibroblasts. J. Biol. Chem. 1979; 254:4186-4190. [PubMed: 220235] 
43. Innerarity TL, Friedlander EJ, Rall SC, Weisgraber KH, Mahley RW. The receptor-binding domain of human apolipoprotein E: Binding of apolipoprotein E fragments. J. Biol. Chem. 1983; 258:12341-12347. [PubMed: 6313652]

44. Irie F, Fitzpatrick AL, Lopez OL, Kuller LH, Peila R, Newman AB, Launer LJ. Enhanced risk for Alzheimer disease in persons with type 2 diabetes and APOE epsilon4: the Cardiovascular Health Study Cognition Study. Arch Neurol. Jan; 2008 65(1):89-93. doi: 10.1001/archneurol.2007.29. doi: 10.1001/archneurol.2007.29. [PubMed: 18195144]

45. Ishibashi S, Brown MS, Goldstein JL, Gerard RD, Hammer RE, Herz J. Hypercholesterolemia in low density lipoprotein receptor knockout mice and its reversal by adenovirus-mediated gene delivery. J Clin Invest. Aug; 1993 92(2):883-93. doi: 10.1172/JCI116663. [PubMed: 8349823]

46. Jeon H, Blacklow SC. Structure and physiologic function of the low-density lipoprotein receptor. Annu Rev Biochem. 2005; 74:535-62. DOI: 10.1146/annurev.biochem.74.082803.133354. [PubMed: 15952897]

47. Johnson LA, Kim HS, Knudson MJ, Nipp CT, Yi X, Maeda N. Diabetic atherosclerosis in APOE*4 mice: synergy between lipoprotein metabolism and vascular inflammation. J Lipid Res. Feb; 2013 54(2):386-96. doi: 10.1194/jlr.M031435. [PubMed: 23204275]

48. Karagiannides I, Abdou R, Tzortzopoulou A, Voshol PJ, Kypreos KE. Apolipoprotein E predisposes to obesity and related metabolic dysfunctions in mice. FEBS J. 2008; 275:4796-4809. doi: 10.1111/j.1742-4658.2008.06619.x. [PubMed: 18754772]

49. Katsouri L, Georgopoulos S. Lack of LDL receptor enhances amyloid deposition and decreases glial response in an Alzheimer's disease mouse model. PLoS One. 2011; 6(7):e21880. doi: 10.1371/journal.pone.0021880. [PubMed: 21755005]

50. Kim J, Castellano JM, Jiang H, Basak JM, Parsadanian M, Pham V, Mason SM, Paul SM, Holtzman DM. Overexpression of low-density lipoprotein receptor in the brain markedly inhibits amyloid deposition and increases extracellular A beta clearance. Neuron. Dec 10; 2009 64(5):63244. doi: 10.1016/j.neuron.2009.11.013. [PubMed: 20005821]

51. Kim J, Jiang H, Park S, Eltorai AE, Stewart FR, Yoon H, Basak JM, Finn MB, Holtzman DM. Haploinsufficiency of human APOE reduces amyloid deposition in a mouse model of amyloid- $\beta$ amyloidosis. J Neurosci. Dec 7; 2011 31(49):18007-12. doi: 10.1523/JNEUROSCI.3773-11.2011. [PubMed: 22159114]

52. Kim TY, Chung HG, Shin HS, Kim SJ, Choi JH, Chung MY, An SK, Choi TK, So HS, Cho HS. Apolipoprotein E Gene Polymorphism, Alcohol Use, and Their Interactions in Combat-Related Post Traumatic Stress Disorder. Depress Anxiety. Jun 12.2013 doi: 10.1002/da.22138.

53. Knouff C, Hinsdale ME, Mezdour H, Altenburg MK, Watanabe M, Quarfordt SH, Sullivan PM, Maeda N. ApoE structure determines VLDL clearance and atherosclerosis risk in mice. J Clin Invest. Jun; 1999 103(11):1579-86. doi: 10.1172/JCI6172. [PubMed: 10359567]

54. Knouff C, Malloy S, Wilder J, Altenburg MK, Maeda N. Doubling expression of the low density lipoprotein receptor by truncation of the $3^{\prime}$-untranslated region sequence ameliorates type iii hyperlipoproteinemia in mice expressing the human apoe2 isoform. J Biol Chem. Feb 9; 2001 276(6):3856-62. doi: 10.1074/jbc.M009423200. [PubMed: 11076954]

55. Knouff C, Briand O, Lestavel S, Clavey V, Altenburg M, Maeda N. Defective VLDL metabolism and severe atherosclerosis in mice expressing human apolipoprotein $\mathrm{E}$ isoforms but lacking the LDL receptor. Biochim Biophys Acta. 2004; 1684:8-1. doi: 10.1016/j.bbalip.2004.03.004. [PubMed: 15450205]

56. Kornecook TJ, McKinney AP, Ferguson MT, Dodart JC. Isoform-specific effects of apolipoprotein $\mathrm{E}$ on cognitive performance in targeted-replacement mice overexpressing human APP. Genes Brain Behav. Mar 1; 2010 9(2):182-92. doi: 10.1111/j.1601-183X.2009.00545.x. [PubMed: 20002203]

57. Kota LN, Shankarappa BM, Shivakumar P, Sadanand S, Bagepally BS, Krishnappa SB, Purushottam M, Sivakumar PT, Jain S, Varghese M, Bharath S. Dementia and diabetes mellitus: association with apolipoprotein e4 polymorphism from a hospital in southern India. Int J Alzheimers Dis. 2012; 2012:702972. doi: 10.1155/2012/702972. [PubMed: 22701197]

58. LaDu MJ, Falduto MT, Manelli AM, Reardon CA, Getz GS, Frail DE. Isoform-specific binding of apolipoprotein E to $\beta$-amyloid. J Biol Chem. 1994; 269(38):23403-23406. [PubMed: 8089103] 
59. Lefterov I, Bookout A, Wang Z, Staufenbiel M, Mangelsdorf D, Koldamova R. Expression profiling in APP23 mouse brain: inhibition of Abeta amyloidosis and inflammation in response to LXR agonist treatment. Mol Neurodegener. Oct 22.2007 2:20. doi: 10.1186/1750-1326-2-20. [PubMed: 17953774]

60. Mahley RW, Rall SC Jr. Apolipoprotein E: far more than a lipid transport protein. Annu Rev Genomics Hum Genet. 2000; 1:507-37. DOI: 10.1146/annurev.genom.1.1.507. [PubMed: 11701639]

61. Mahley RW, Weisgraber KH, Huang Y. Apolipoprotein E4: a causative factor and therapeutic target in neuropathology, including Alzheimer's disease. Proc Natl Acad Sci U S A. Apr 11; 2006 103(15):5644-51. doi: 10.1073/pnas.0600549103. [PubMed: 16567625]

62. Malloy SI, Altenburg MK, Knouff C, Lanningham-Foster L, Parks JS, Maeda N. Harmful effects of increased LDLR expression in mice with human APOE*4 but not APOE*3. Arterioscler Thromb Vasc Biol. 2004; 24(1):91-7. doi: 10.1161/01.ATV.0000094963.07902.FB. [PubMed: 12969990]

63. Marchant NL, Reed BR, Sanossian N, Madison CM, Kriger S, Dhada R, Mack WJ, DeCarli C, Weiner MW, Mungas DM, Chui HC, Jagust WJ. The aging brain and cognition: contribution of vascular injury and aß to mild cognitive dysfunction. JAMA Neurol. Apr; 2013 70(4):488-95. doi: 10.1001/2013.jamaneurol.405. [PubMed: 23400560]

64. Maren S. Neurobiology of Pavlovian fear conditioning. Annu Rev Neurosci. 2001; 24:897-931. DOI: 10.1146/annurev.neuro.24.1.89. [PubMed: 11520922]

65. Martin M, Dotti CG, Ledesma MD. Brain cholesterol in normal and pathological aging. Biochim Biophys Acta. Aug; 2010 1801(8):934-44. doi: 10.1016/j.bbalip.2010.03.011. [PubMed: 20359547]

66. Marques-Vidal P, Bongard V, Ruidavets JB, Fauvel J, Hanaire-Broutin H, Perret B, Ferrieres J. Obesity and alcohol modulate the effect of apolipoprotein E polymorphism on lipids and insulin. Obes Res. 2003; 11:1200-1206. [PubMed: 14569045]

67. Mattevi VS, Coimbra CE, Santos RV, Salzano FM, Hutz MH. Association of the low-density lipoprotein receptor gene with obesity in Native American populations. Hum Genet. 2000; 106:546-552. doi: 10.1007/s004390000299. [PubMed: 10914685]

68. Meewisse ML, Reitsma JB, de Vries GJ, Gersons BP, Olff M. Cortisol and post-traumatic stress disorder in adults: systematic review and meta-analysis. Br J Psychiatry. Nov.2007 191:387-92. doi: 10.1192/bjp.bp.106.024877. [PubMed: 17978317]

69. Mulder M, Jansen PJ, Janssen BJ, van de Berg WD, van der Boom H, Havekes LM, de Kloet RE, Ramaekers FC, Blokland A. Low-density lipoprotein receptor-knockout mice display impaired spatial memory associated with a decreased synaptic density in the hippocampus. Neurobiol Dis. Jun; 2004 16(1):212-9. doi: 10.1016/j.nbd.2004.01.015. [PubMed: 15207278]

70. Oitzl MS, Mulder M, Lucassen PJ, Havekes LM, Grootendorst J, de Kloet ER. Severe learning deficits in apolipoprotein E-knockout mice in a water maze task. Brain Res. Mar 28; 1997 752(1-2):189-96. Doi: 10.1016/S0006-8993(96)01448-5. [PubMed: 9106456]

71. Olsen RH, Agam M, Davis MJ, Raber J. ApoE isoform-dependent deficits in extinction of contextual fear conditioning. Genes Brain Behav. Oct; 2012 11(7):806-12. doi: 10.1111/j. 1601-183X.2012.00833.x. [PubMed: 22883220]

72. Oh JY, Barrett-Connor E. Apolipoprotein E polymorphism and lipid levels differ by gender and family history of diabetes: the Rancho Bernardo Study. Clin Genet. 2001; 60:132-137. DOI: 10.1034/j.1399-0004.2001.600207.x. [PubMed: 11553047]

73. Peila R, Rodriguez BL, Launer LJ. Honolulu-Asia Aging Study. Type 2 diabetes, APOE gene, and the risk for dementia and related pathologies: The Honolulu-Asia Aging Study. Diabetes. Apr; 2002 51(4):1256-62. [PubMed: 11916953]

74. Porter VR, Buxton WG, Fairbanks LA, Strickland T, O'Connor SM, Rosenberg-Thompson S, Cummings JL. Frequency and characteristics of anxiety among patients with Alzheimer's disease and related dementias. Journal of Neuropsychiatry and Clinical Neurosciences. 2003; 15(2):180186. doi: 10.1176/appi.neuropsych.15.2.180. [PubMed: 12724459]

75. Raber J, Wong D, Buttini M, Orth M, Bellosta S, Pitas RE, Mahley RW, Mucke L. Isoformspecific effects of human apolipoprotein $\mathrm{E}$ on brain function revealed in ApoE knockout mice: 
increased susceptibility of females. Proc Natl Acad Sci U S A. Sep 1; 1998 95(18):10914-9. [PubMed: 9724804]

76. Raber J, Wong D, Yu GQ, Buttini M, Mahley RW, Pitas RE. Mucke L Apolipoprotein E and cognitive performance. Nature. Mar 23; 2000 404(6776):352-4. doi:10.1038/35006165. [PubMed: 10746713]

77. Raber J, Huang Y, Ashford JW. ApoE genotype accounts for the vast majority of AD risk and AD pathology. Neurobiol Aging. May-Jun;2004 25(5):641-50. doi: 10.1016/j.neurobiolaging. 2003.12.023. [PubMed: 15172743]

78. Raber J. Role of apolipoprotein E in anxiety. Neural Plast. 2007; 2007:91236. doi: 10.1155/2007/91236. [PubMed: 17710250]

79. Ramakrishnan G, Arjuman A, Suneja S, Das C, Chandra NC. The association between insulin and low-density lipoprotein receptors. Diab Vasc Dis Res. Jul; 2012 9(3):196-204. doi: 10.1177/1479164111430243. [PubMed: 22278734]

80. Ramaswamy G, Xu Q, Huang Y, Weisgraber KH. Effect of domain interaction on apolipoprotein E levels in mouse brain. J Neurosci. Nov 16; 2005 25(46):10658-63. doi: 10.1523/JNEUROSCI. 1922-05.2005. [PubMed: 16291938]

81. Retz W, Thome J, Durany N, Harsányi A, Retz-Junginger P, Kornhuber J, Riederer P, Rösler M. Potential genetic markers of sporadic Alzheimer's dementia. Psychiatr Genet. Sep; 2001 11(3): 115-22. [PubMed: 11702052]

82. Riddell DR, Zhou H, Atchison K, Warwick HK, Atkinson PJ, Jefferson J, Xu L, Aschmies S, Kirksey Y, Hu Y, Wagner E, Parratt A, Xu J, Li Z, Zaleska MM, Jacobsen JS, Pangalos MN, Reinhart PH. Impact of apolipoprotein E (ApoE) polymorphism on brain ApoE levels. J Neurosci. Nov 5; 2008 28(45):11445-53. doi: 10.1523/JNEUROSCI.1972-08.2008. [PubMed: 18987181]

83. Robertson J, Curley J, Kaye J, Quinn J, Pfankuch T, Raber J. ApoE isoforms and measures of anxiety in probable AD patients and Apoe-/- mice. Neurobiol Aging. May; 2005 26(5):637-43. doi: 10.1016/j.neurobiolaging.2004.06.003. [PubMed: 15708438]

84. Ruiz J, Kouiavskaia D, Migliorini M, Robinson S, Saenko EL, Gorlatova N, Li D, Lawrence D, Hyman BT, Weisgraber KH, Strickland DK. The apoE isoform binding properties of the VLDL receptor reveal marked differences from LRP and the LDL receptor. J Lipid Res. Aug; 2005 46(8): 1721-31. doi: 10.1194/jlr.M500114-JLR200. [PubMed: 15863833]

85. Schreyer SA, Vick C, Lystig TC, Mystkowski P, LeBoeuf RC. LDL receptor but not apolipoprotein $\mathrm{E}$ deficiency increases diet-induced obesity and diabetes in mice. Am J Physiol Endocrinol Metab. Jan; 2002 282(1):E207-14. [PubMed: 11739102]

86. Shepherd JK, Grewal SS, Fletcher A, Bill DJ, Dourish CT. Behavioural and pharmacological characterisation of the elevated "zero-maze" as an animal model of anxiety. Psychopharmacology (Berl). Sep; 1994 116(1):56-64. [PubMed: 7862931]

87. Sima A, Iordan A, Stancu C. Apolipoprotein E polymorphism - a risk factor for metabolic syndrome. Clin Chem Lab Med. 2007; 45:1149-1153. DOI: 10.1515/CCLM.2007.258. [PubMed: 17848120]

88. Spijker S. Neuroproteomics. Chapter 2: Dissection of Rodent Brain Regions. May 25.2011 57:1326. DOI: $10.1007 / 978-1-61779-111-6$.

89. Stonnington CM, Locke DE, Dueck AC, Caselli RJ. Anxiety affects cognition differently in healthy apolipoprotein E $\varepsilon 4$ homozygotes and non-carriers. J Neuropsychiatry Clin Neurosci. 2011; 23(3):294-9. Summer doi: 10.1176/appi.neuropsych.23.3.294. [PubMed: 21948890]

90. Sullivan PM, Mezdour H, Aratani Y, Knouff C, Najib J, Reddick RL, Quarfordt SH, Maeda N. Targeted replacement of the mouse apolipoprotein E gene with the common human APOE3 allele enhances diet-induced hypercholesterolemia and atherosclerosis. J Biol Chem. Jul 18; 1997 272(29):17972-80. doi: 10.1074/jbc.272.29.17972. [PubMed: 9218423]

91. Sullivan PM, Mezdour H, Quarfordt SH, Maeda N. Type III hyperlipoproteinemia and spontaneous atherosclerosis in mice resulting from gene replacement of mouse Apoe with human Apoe*2. J Clin Invest. Jul 1; 1998 102(1):130-5. doi: 10.1172/JCI2673. [PubMed: 9649566]

92. Sullivan PM, Mace BE, Maeda N, Schmechel DE. Marked regional differences of brain human apolipoprotein E expression in targeted replacement mice. Neuroscience. 2004; 124(4):725-33. doi: 10.1016/j.neuroscience.2003.10.011. [PubMed: 15026113] 
93. Sullivan PM, Han B, Liu F, Mace BE, Ervin JF, Wu S, Koger D, Paul S, Bales KR. Reduced levels of human apoE4 protein in an animal model of cognitive impairment. Neurobiol Aging. May; 2011 32(5):791-801. doi: 10.1016/j.neurobiolaging.2009.05.011. [PubMed: 19577821]

94. Tai LM, Bilousova T, Jungbauer L, Roeske SK, Youmans KL, Yu C, Poon WW, Cornwell LB, Miller CA, Vinters HV, Van Eldik LJ, Fardo DW, Estus S, Bu G, Gylys KH, Ladu MJ. Levels of soluble apolipoprotein E/amyloid- $\beta$ (A $\beta)$ complex are reduced and oligomeric $A \beta$ increased with APOE4 and Alzheimer disease in a transgenic mouse model and human samples. J Biol Chem. Feb 22; 2013 288(8):5914-26. doi: 10.1074/jbc.M112.442103. [PubMed: 23293020]

95. Terwel D, Steffensen KR, Verghese PB, Kummer MP, Gustafsson JÅ, Holtzman DM, Heneka MT. Critical role of astroglial apolipoprotein $\mathrm{E}$ and liver $\mathrm{X}$ receptor-a expression for microglial $\mathrm{A} \beta$ phagocytosis. J Neurosci. May 11; 2011 31(19):7049-59. doi: 10.1523/JNEUROSCI. 6546-10.2011. [PubMed: 21562267]

96. Tokuda T, Calero M, Matsubara E, Vidal R, Kumar A, Permanne B, Zlokovic B, Smith JD, Ladu MJ, Rostagno A, Frangione B, Ghiso J. Lipidation of apolipoprotein E influences its isoformspecific interaction with Alzheimer's amyloid $\beta$ peptides. Biochem J. 2000; 348(pt 2):359-365. [PubMed: 10816430]

97. Trommer BL, Shah C, Yun SH, Gamkrelidze G, Pasternak ES, Ye GL, Sotak M, Sullivan PM, Pasternak JF, LaDu MJ. ApoE isoform affects LTP in human targeted replacement mice. Neuroreport. Dec 3; 2004 15(17):2655-8. [PubMed: 15570172]

98. Trommer BL, Shah C, Yun SH, Gamkrelidze G, Pasternak ES, Stine WB, Manelli A, Sullivan P, Pasternak JF, LaDu MJ. ApoE isoform-specific effects on LTP: blockade by oligomeric amyloidbeta1-42. Neurobiol Dis. Feb; 2005 18(1):75-82. doi: 10.1016/j.nbd.2004.08.011. [PubMed: 15649697]

99. van Meer P, Acevedo S. Raber J Impairments in spatial memory retention of GFAP-apoE4 female mice. Behav Brain Res. Jan 25; 2007 176(2):372-5. doi: 10.1016/j.bbr.2006.10.024. [PubMed: 17126420]

100. Veinbergs I, Mallory M, Mante M, Rockenstein E, Gilbert JR, Masliah E. Differential neurotrophic effects of apolipoprotein E in aged transgenic mice. Neurosci Lett. Apr 23; 1999 265(3):218-22. doi: 10.1016/S0304-3940(99)00243-8. [PubMed: 10327170]

101. Versmissen J, Oosterveer DM, Hoekstra M, Out R, Berbée JF, Blommesteijn-Touw AC, van Vark-van der Zee L, Vongpromek R, Vanmierlo T, Defesche JC, Mulder M, Kastelein JJ, Sijbrands EJ. Apolipoprotein isoform E4 does not increase coronary heart disease risk in carriers of low-density lipoprotein receptor mutations. Circ Cardiovasc Genet. Dec; 2011 4(6):655-60. doi: 10.1161/CIRCGENETICS.111.959858. [PubMed: 22010136]

102. Volcik KA, Barkley RA, Hutchinson RG, Mosley TH, Heiss G, Sharrett AR, Ballantyne CM, Boerwinkle E. Apolipoprotein E polymorphisms predict low density lipoprotein cholesterol levels and carotid artery wall thickness but not incident coronary heart disease in 12,491 ARIC study participants. Am J Epidemiol. 2006; 164:342-348. doi: 10.1093/aje/kwj202. [PubMed: 16760224]

103. Vorhees CV, Williams MT. Morris water maze: procedures for assessing spatial and related forms of learning and memory. Nat Protoc. 2006; 1(2):848-58. doi: 10.1038/nprot.2006.116. [PubMed: 17406317]

104. Weisgraber KH, Innerarity TL, Mahley RW. Abnormal lipoprotein receptor-binding activity of the human E apoprotein due to cysteinearginine interchange at a single site. J. Biol. Chem. 1982; 257:2518-2521. [PubMed: 6277903]

105. Yamamoto T, Choi HW, Ryan RO. Apolipoprotein E isoform-specific binding to the low-density lipoprotein receptor. Anal Biochem. Jan 15; 2008 372(2):222-6. doi: 10.1016/j.ab.2007.09.005. [PubMed: 17923100]

106. Yu C, Youmans KL, LaDu MJ. Proposed mechanism for lipoprotein remodelling in the brain. Biochim Biophys Acta. Aug; 2010 1801(8):819-23. doi: 10.1016/j.bbalip.2010.05.001. [PubMed: 20470897]

107. Zou F, Gopalraj RK, Lok J, Zhu H, Ling IF, Simpson JF, Tucker HM, Kelly JF, Younkin SG, Dickson DW, Petersen RC, Graff-Radford NR, Bennett DA, Crook JE, Younkin SG, Estus S. Sex-dependent Association of a Common Low Density Lipoprotein Receptor Polymorphism with 
RNA Splicing Efficiency in the Brain and Alzheimers Disease. Hum Mol Genet. Apr 1; 2008 17(7):929-935. doi: 10.1093/hmg/ddm365. [PubMed: 18065781] 


\section{Highlights}

- ApoE isoform-dependent interactions with hLDLR affect plasma and brain apoE levels

- LDLR deficient mice show apoE isoform-independent impairment in spatial memory

- hLDLR mice with E4 have less long-term spatial memory than those with E2 and E3

- In hLDLR mice, hippocampal apoE levels positively correlate with spatial memory 


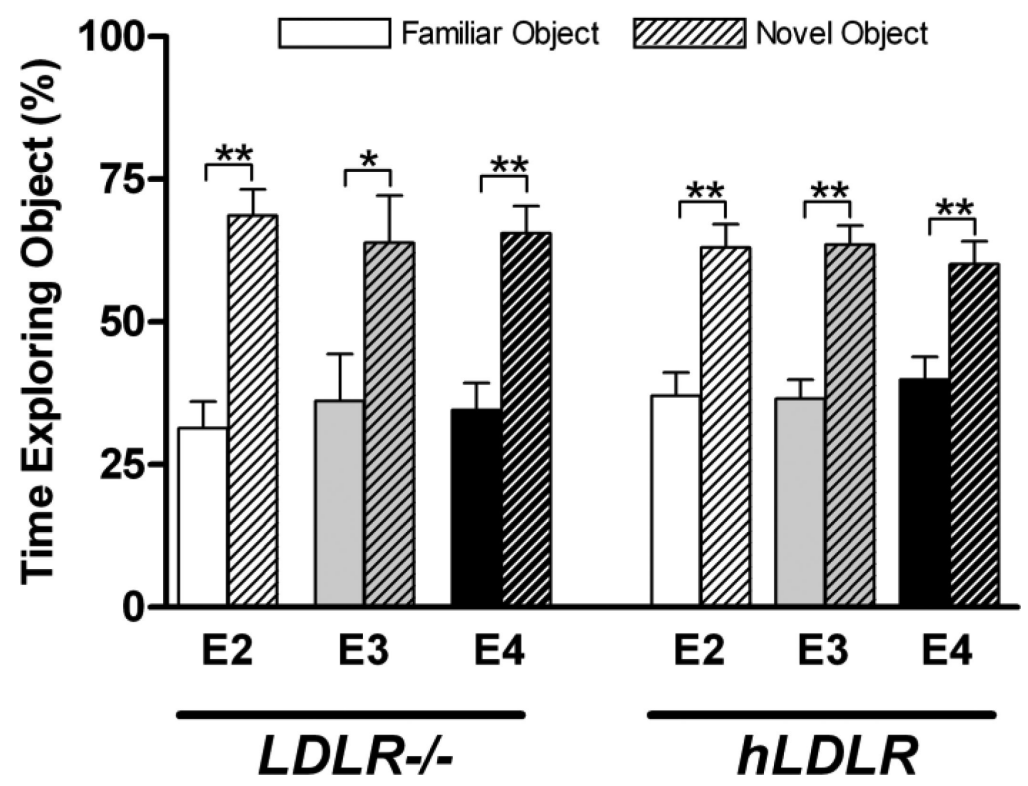

Figure 1.

Niether $L D L R$ nor $A P O E$ genotype affect recognition memory in the novel object recognition test. On Day 1, mice are exposed to two identical ("Familiar") objects for 15 minutes. On Day 2, one of the "Familiar" objects is replaced with a unique "Novel" object of identical dimensions. Exploration of the objects on Day 2 was video tracked and analyzed as percent time spent examining each object. $n=6-10$ per group. $(6,8,8,10,6,8) .{ }^{*} p<0.05$, $* * p<0.01$ 
A
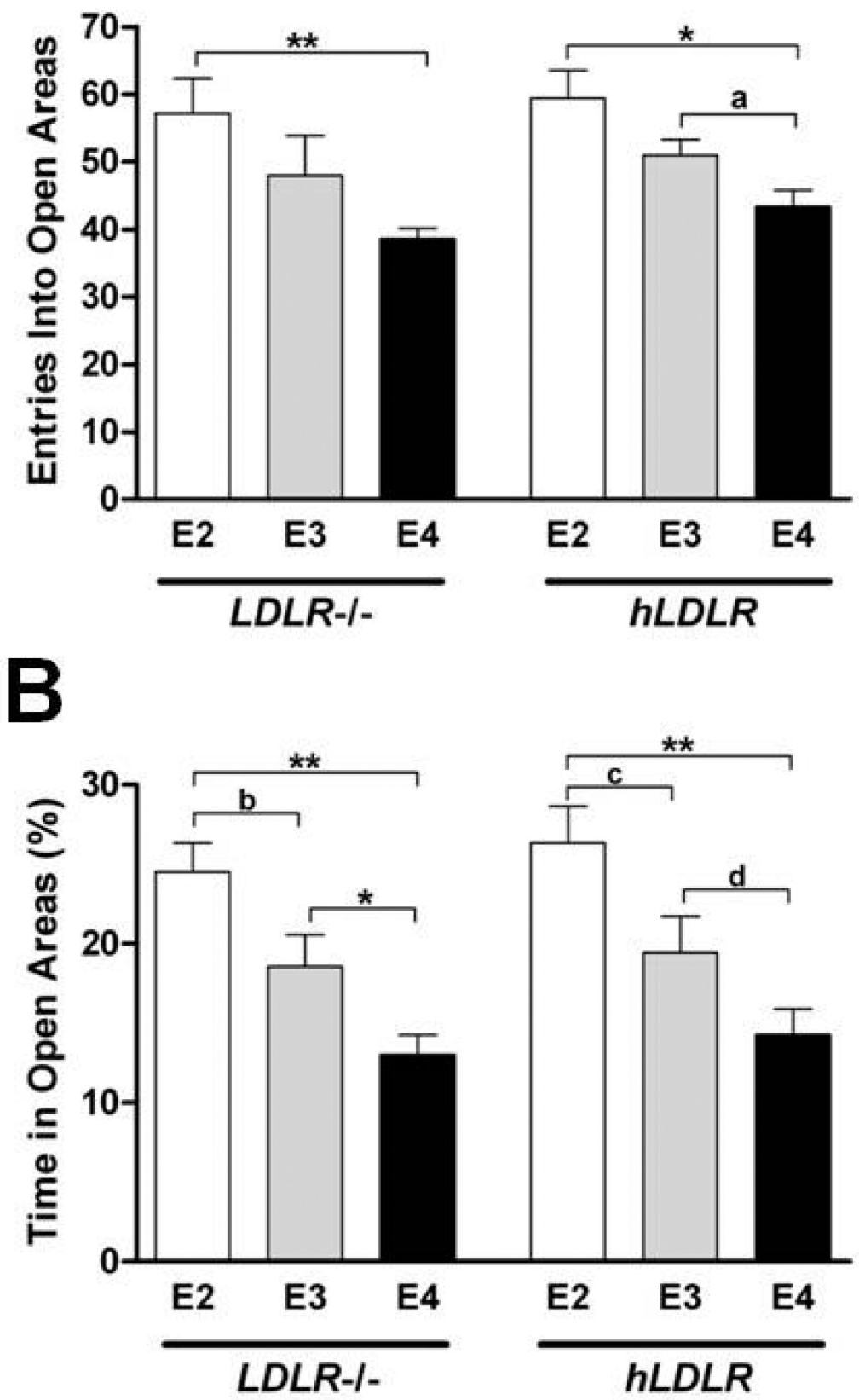

Figure 2.

APOE genotype affects anxiety like behavior in the elevated zero maze independent of LDLR. The circular, elevated zero maze consists of two separate dark, walled-in "Closed" sections and two bright, exposed "Open" sections. Mice were placed into the center of one "Closed" section and given 15 minutes to explore. A) Number of full-body entries made into the "Open" section from the "Closed" portion of the maze. B) Percent time spent in the anxiety provoking "Open" section of the maze. $* p<0.05, * * p<0.01,{ }^{\mathrm{a}} p=0.053,{ }^{\mathrm{b}} p=$ $0.06,{ }^{\mathrm{c}} p=0.08,{ }^{\mathrm{d}} p=0.09 . n=7-10$ mice per group. 

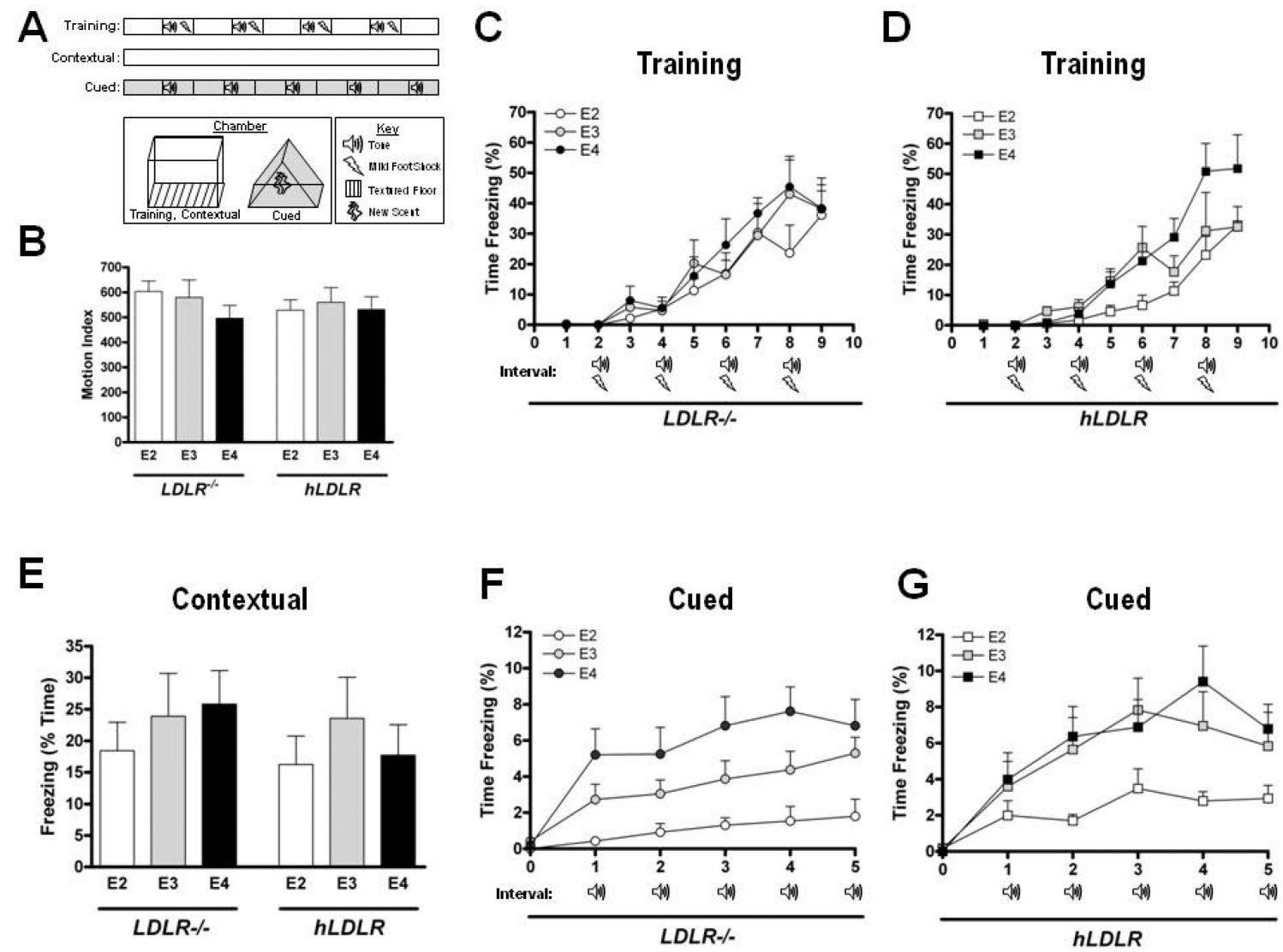

Figure 3.

Contextual fear conditioning is unaffected by $L D L R$ and APOE. Cued fear conditioning responses are determined by $A P O E$ genotype independent of the LDLR. A) Experimental design. B) Response to conditioned stimulus. The activity of the mice during the two second $0.35 \mathrm{~mA}$ footshock. C-D) Fear Conditioning Training. Time spent freezing (cessation of movement with the exception of respiration) was analyzed by video software during the training session. E) Contextual Fear Conditioning. Twenty four hours following training, mice were exposed to an identical chamber and scent for 10 minutes and time freezing was analyzed. F-G) Cued Fear Conditioning. Immediately following re-exposure to the context, mice were placed in a novel environment (unique chamber, floor texture and scent) and reexposed to five subsequent cues (tone). $n=6-11$ mice per group. 

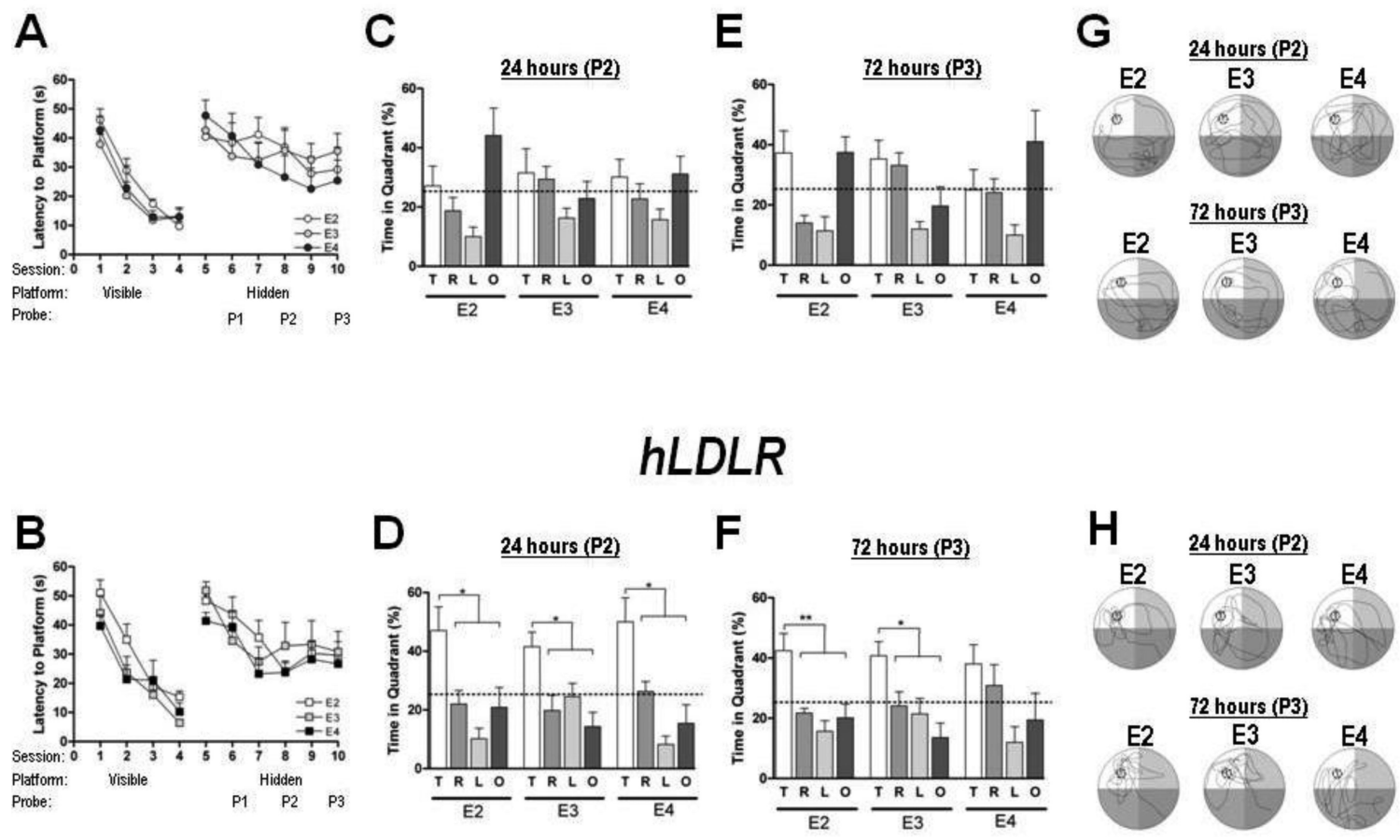

Figure 4.

LDLR deficiency results in severe spatial memory impairment, regardless of APOE genotype. Mice with human LDLR and apoE4, but not apoE2 or apoE3, show impaired long term spatial memory. A-B) Latency to platform was analyzed during the "Visible" (left curve) and "Hidden" (right curve) trials to generate learning curves in mice lacking the LDLR (A), and in mice with human LDLR (B). Timing of the probe trials are marked with arrows. C-D) Probe trial, 24 hours. Time spent in each quadrant during a 60 second probe trial, conducted 18 hours following the fourth "Hidden" training session. E-F) Probe trial, 72 hours. Time spent in each quadrant during a 60 second probe trial, conducted 72 hours following the sixth "Hidden" training session. G-H) Representative swim pattern of E2, E3 and E4 mice with no LDLR (G) or human LDLR (H) during the 24 hour (top row) and 72 hour (bottom row) probe trials. Representative tracings were chosen based on the median value for time spent in target quadrant for each group. * $p<0.05, * * p<0.01, n=7-10$ per group. 
$\varpi$ Cortex $\rightleftharpoons$ Hippocampus

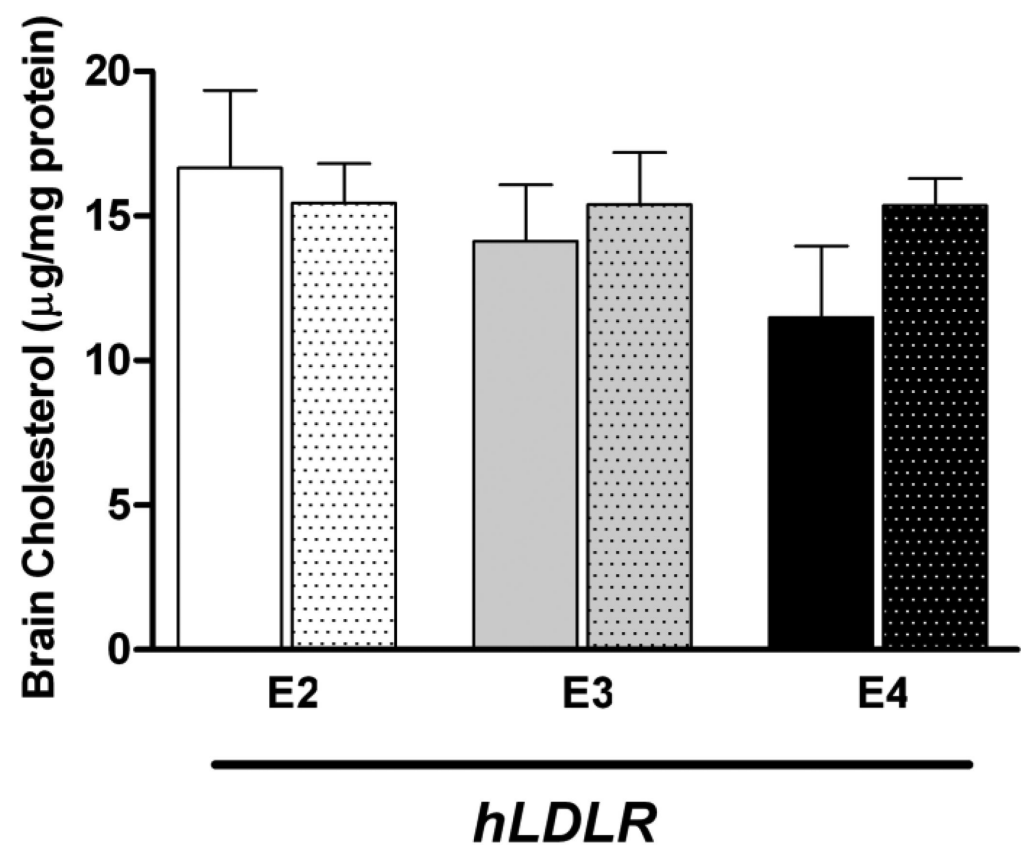

Figure 5.

Cortex and hippocampus cholesterol concentrations in mice with human LDLR. Cholesterol concentrations were measured by GC/MS in the cortex and hippocampus of human LDLR mice. $n=6-10$ mice per group. 


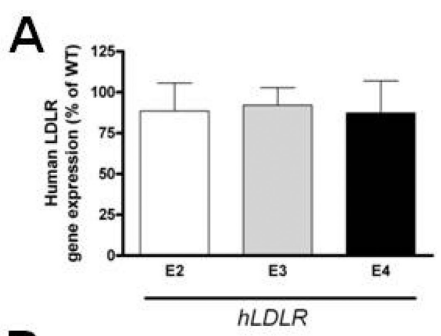

B

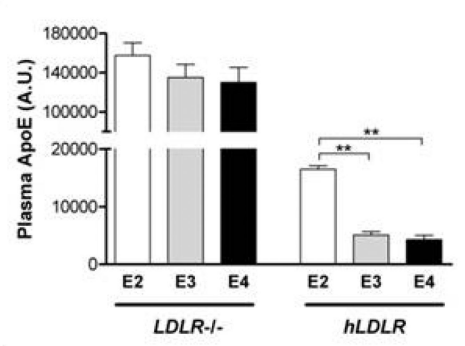

C

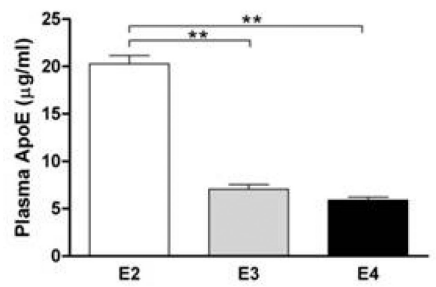

D

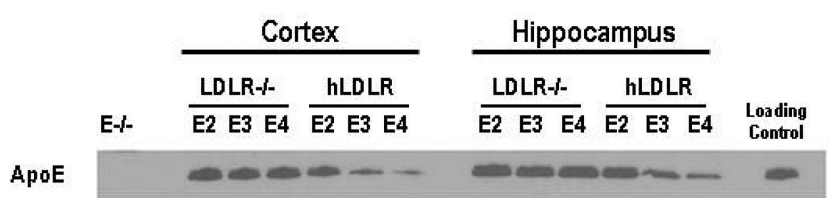

E

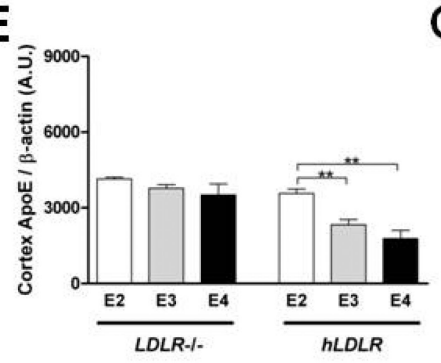

G

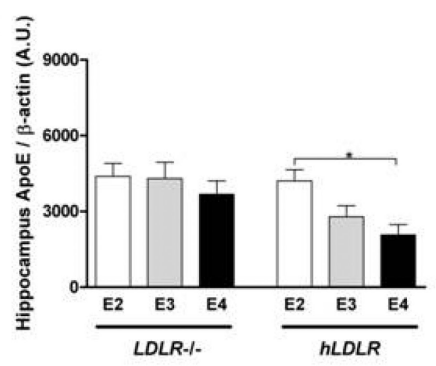

$\mathbf{F}$

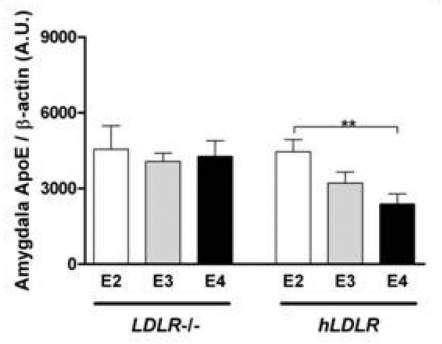

$\mathrm{H}$

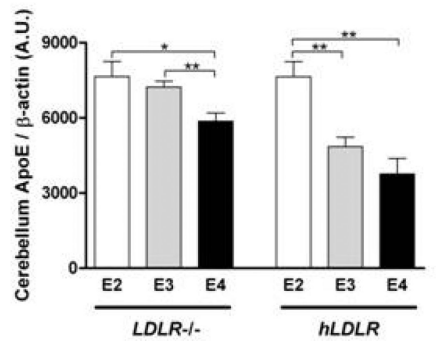

Figure 6.

Human $L D L R$ expression is similar in E2, E3 and E4 mice. Plasma and brain apoE levels are modulated by both $L D L R, A P O E$ and an $A P O E^{*} L D L R$ interaction. A) LDLR gene expression. mRNA was purified from mouse brain (cortex) and real time PCR performed. $\mathrm{n}$ $=6-8$ per group. Values are normalized to Gapdh gene expression and expressed as a percent of average LDLR expression in wild type mice $(n=7)$. B) Plasma apoE (Western blot). Plasma was collected following a four hour fast and apoE was measured by western blot in $1 \mu \mathrm{l}$ of plasma ( $0.1 \mu \mathrm{l}$ for LDLR-/- samples). Band intensities were calculated using Image $\mathbf{J}$ software. C) Plasma apoE (ELISA) in human LDLR mice. Plasma was diluted 3000-fold in PBS-T and apoE levels were measured using a sandwich ELISA. Samples were run in triplicate and normalized to a standard curve generated using recombinant human apoE. D) Representative blots of apoE in the cortex and hippocampus. E-H) Regional brain apoE. ApoE in the cortex $(\mathrm{E})$, amygdala $(\mathrm{F})$, hippocampus $(\mathrm{G})$ and cerebellum $(\mathrm{H})$ was measured by western blot. Band intensities were calculated using Image $\mathrm{J}$ software and expressed relative to $\beta$-actin. 

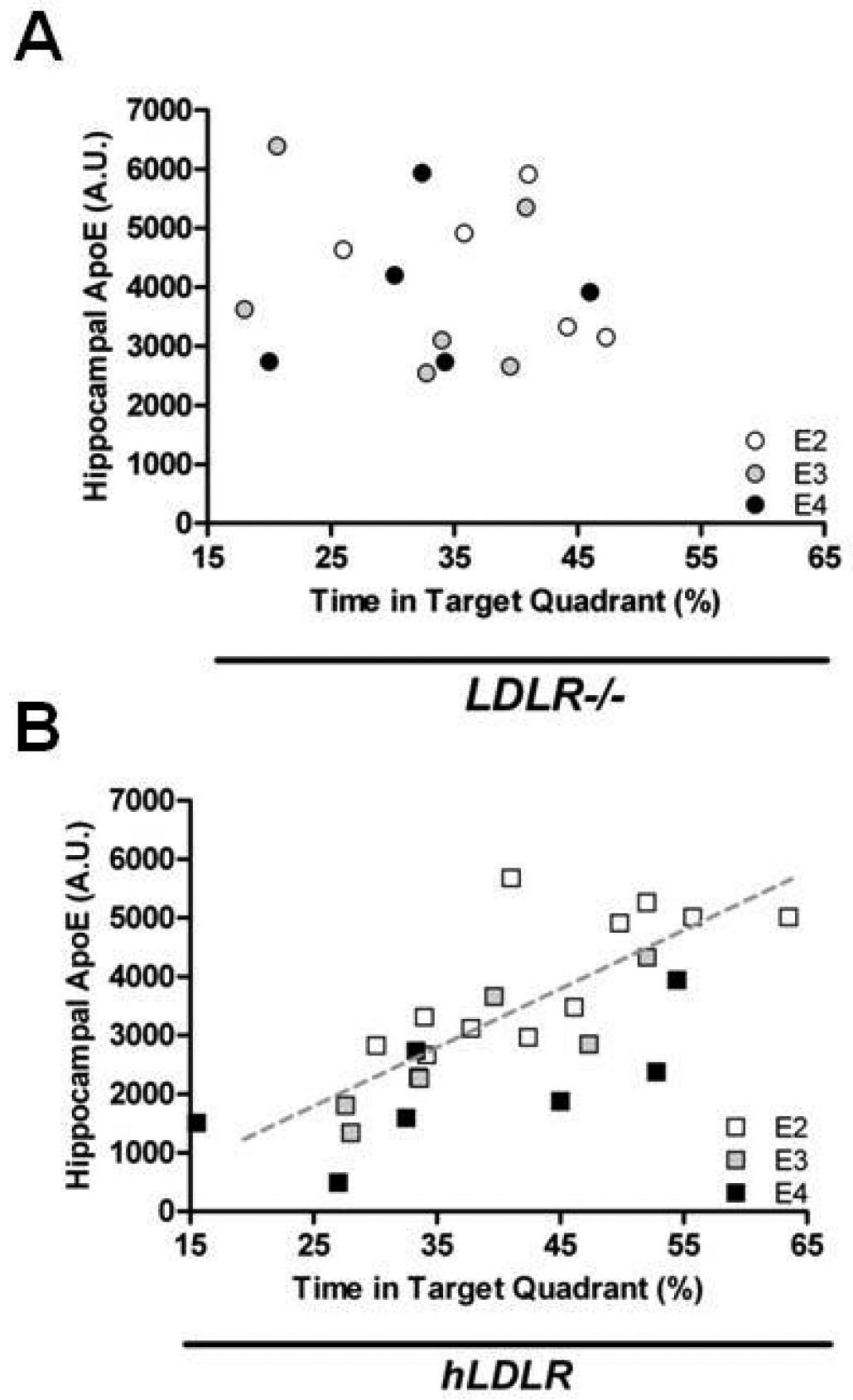

Figure 7.

Hippocampal ApoE correlates with spatial memory retention in mice with human LDLR. AB) Correlation between hippocampal apoE levels and long term (72 hours) spatial memory retention. ApoE levels in the hippocampus positively correlate with the percent time spent in the target quadrant in mice with human LDLR (B), but not in $\operatorname{LDLR}^{-/}$mice (A). $n=6-12$ mice per group. 


\section{Table 1}

Tissue Weights and Fasting Plasma Total Cholesterol in human ApoE mice with or without human LDLR

\begin{tabular}{|c|c|c|c|c|c|c|}
\hline \multirow{2}{*}{ Genotype } & \multicolumn{5}{|c|}{ Tissue Weights } & Plasma \\
\cline { 2 - 7 } \multicolumn{1}{|c|}{} & Body weight (g) & Liver (g) & Adipose (g) & Brain (g) & Cholesterol (mg/dl) \\
\hline \multirow{4}{*}{ LDLR $^{-/-}$} & E2 & $23.94 \pm 1.74(8)$ & $1.108 \pm 0.129(7)$ & $2.037 \pm 0.020(7)$ & $0.453 \pm 0.020(8)$ & $590.4 \pm 194.7(12)$ \\
\cline { 2 - 7 } & E3 & $25.17 \pm 3.58(6)$ & $1.200 \pm 0.239(6)$ & $2.277 \pm 0.048(6)$ & $0.483 \pm 0.048(6)$ & $446.5 \pm 121.8(18)$ \\
\cline { 2 - 7 } & E4 & $23.47 \pm 3.88(6)$ & $1.159 \pm 0.324(6)$ & $2.567 \pm 0.049(6)$ & $0.474 \pm 0.049(6)$ & $371.5 \pm 84.8(12)$ \\
\hline \multirow{3}{*}{ Human LDLR } & E2 & $23.68 \pm 2.34(9)$ & $1.156 \pm 0.145(9)$ & $2.193 \pm 0.048(9)$ & $0.484 \pm 0.048(9)$ & $68.7 \pm 16.1(17)^{*}$ \\
\cline { 2 - 7 } & E3 & $25.35 \pm 4.40(6)$ & $1.194 \pm 0.272(6)$ & $2.222 \pm 0.014(6)$ & $0.466 \pm 0.014(6)$ & $41.4 \pm 16.2(14)$ \\
\cline { 2 - 7 } & E4 & $23.97 \pm 2.52(6)$ & $1.121 \pm 0.174(6)$ & $2.617 \pm 0.031(6)$ & $0.480 \pm 0.031(6)$ & $63.2 \pm 18.7(18)$ \\
\hline
\end{tabular}

Data expressed as mean \pm SEM (n).

1 Total adipose tissue weight ("Adipose") is a combination of visceral (gonadal and retroperitoneal fat pads) and subcutaneous (right and left posterior) fat pads.

2 For

2 For brain weight, the olfactory bulbs and brainstem were removed prior to weighing.

p $<0.05$ compared to E3 and E4.

$\hat{\mathrm{p}}<0.05$ compared to $\mathrm{E} 3$ 
Table 2

Motor Function of human ApoE mice with or without human LDLR

\begin{tabular}{|c|c|c|c|c|}
\hline \multirow{2}{*}{ Genotype } & \multicolumn{3}{|c|}{ Motor Function } \\
\cline { 3 - 5 } \multicolumn{2}{|c|}{} & Open Field Velocity (cm/s) & Rotarod (rpm) & Swim Speed (cm/s) \\
\hline \multirow{4}{*}{ LDLR $^{-/-}$} & E2 & $4.67 \pm 1.01(7)$ & $20.52 \pm 1.54(7)$ & $15.06 \pm 3.61(7)$ \\
\cline { 2 - 5 } & E3 & $4.42 \pm 1.80(8)$ & $19.42 \pm 3.54(8)$ & $16.53 \pm 2.51(8)$ \\
\cline { 2 - 5 } & E4 & $4.80 \pm 0.95(7)$ & $19.46 \pm 6.77(7)$ & $15.96 \pm 3.19(7)$ \\
\hline \multirow{4}{*}{ Human LDLR } & E2 & $5.17 \pm 1.18(10)$ & $21.58 \pm 3.61(10)$ & $16.42 \pm 1.78(10)$ \\
\cline { 2 - 5 } & E3 & $4.63 \pm 1.49(7)$ & $19.17 \pm 3.65(7)$ & $16.90 \pm 2.45(7)$ \\
\cline { 2 - 5 } & E4 & $4.58 \pm 0.82(7)$ & $22.58 \pm 4.04(7)$ & $16.00 \pm 1.32(7)$ \\
\hline
\end{tabular}

Data expressed as mean \pm SEM (n).

${ }^{1}$ Open Field Velocity is the mean velocity $(\mathrm{cm} / \mathrm{s})$ over the course of two 10 minute exposures to the open field arena.

${ }^{2}$ Rotarod rotations per minute (RPM) is the mean of the maximum speed achieved during each of five trials.

${ }^{3}$ Swim speed is the mean swimming velocity $(\mathrm{cm} / \mathrm{s})$ over the course of eight trials during the visible water maze session. 